التعدي على الاراضى الزراعية ونهر النيل وأثارهما على الاقتصاد المصري

( دراسة اقتصادية)

صلاح على صالح فضل الله الهي

قسم الاقتصاد الزراعي ــ كلية الزر اعةـــامعه أسيوط

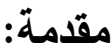

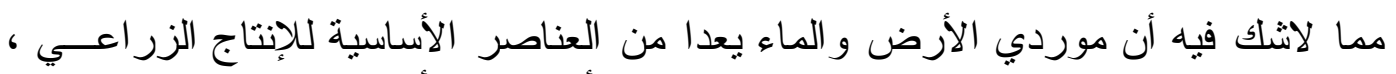

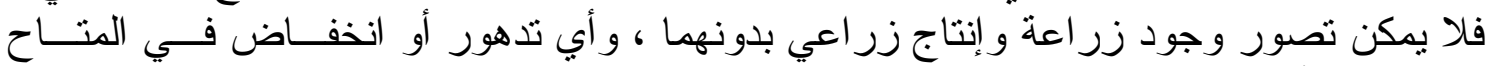

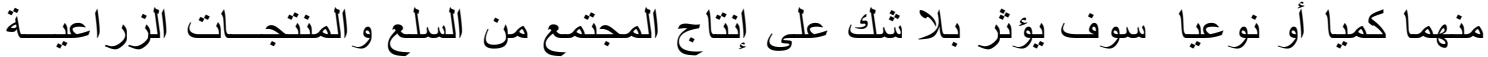

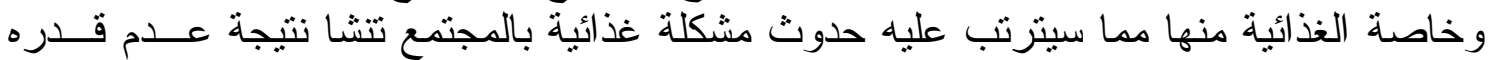

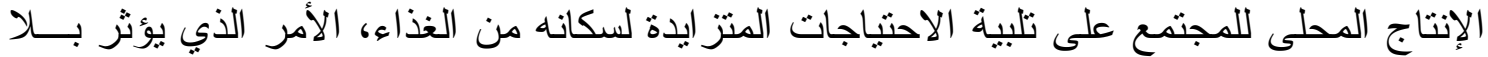

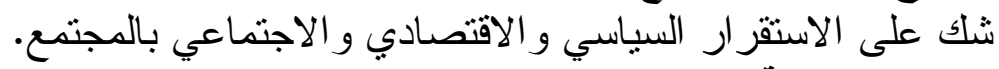

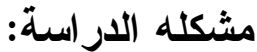

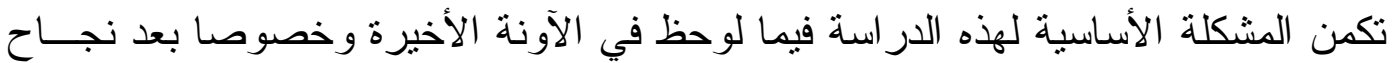

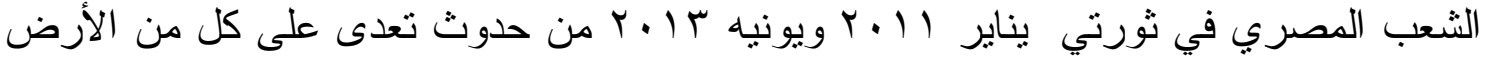

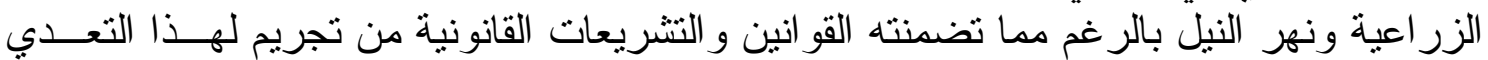

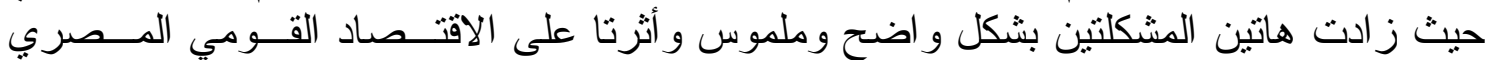
بصفه عامة و الزر اعي على وجنه الخئ الخصوص.

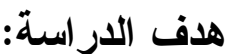

تهذف هذه الدراسة بصفه أساسية إلي إلقاء الضوء على على هاتين المشكلنتين و التعرف علــى

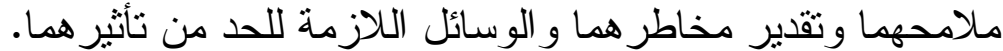
أسلوب الاراسة ومصادر البيانات

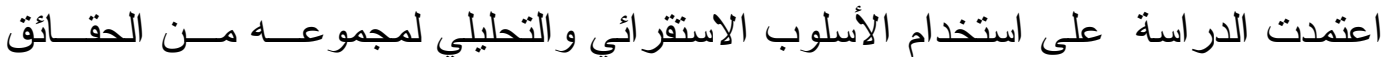

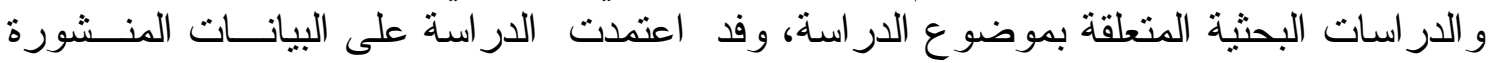

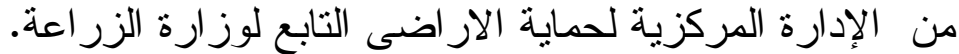

Received on: 17/2/2015

Referees: Prof. Talat H. Ismail
Accepted for publication on: 21/2/2015

Prof. Galal A. El-Sogheir 


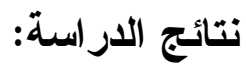

أولا:- الأبعاد الاقتصادية لظاهرة التعدي على الار اضى الزراعية:

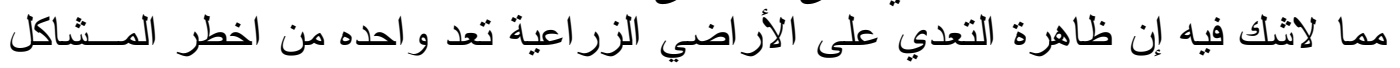

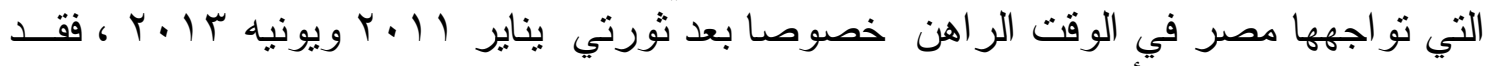

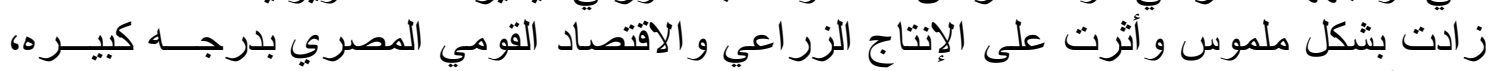

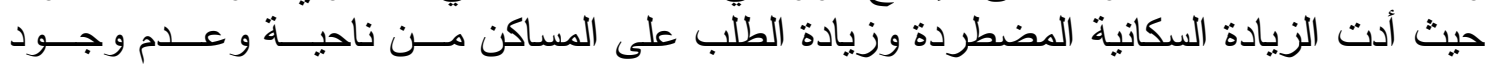

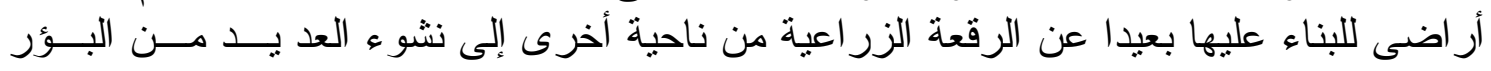

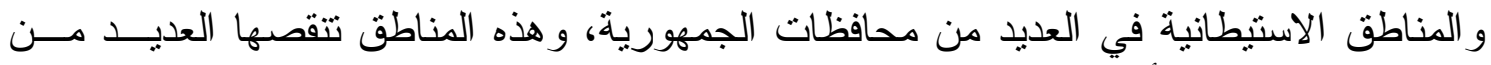

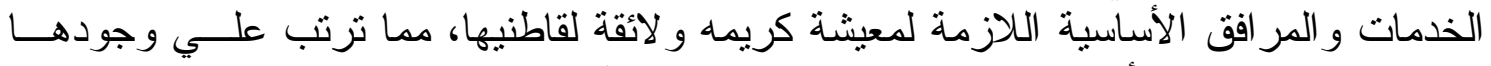

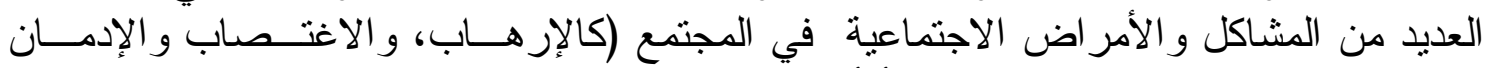

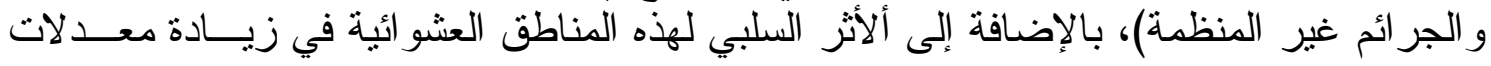

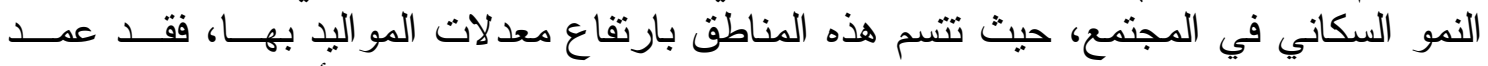

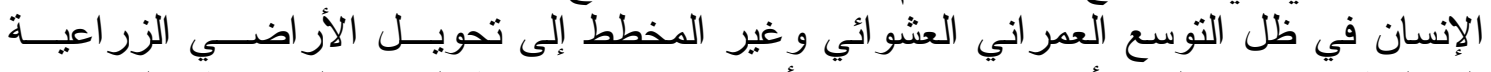

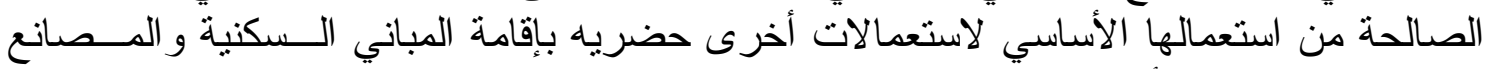

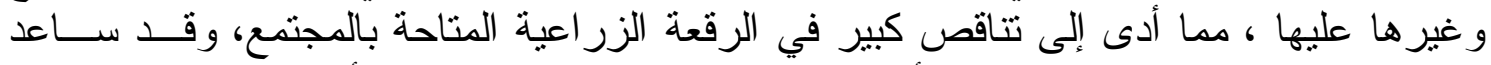

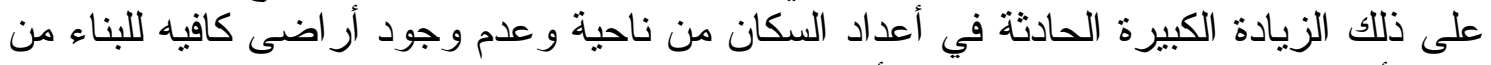

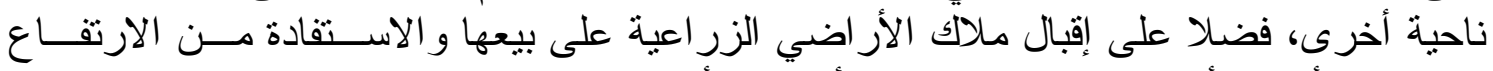

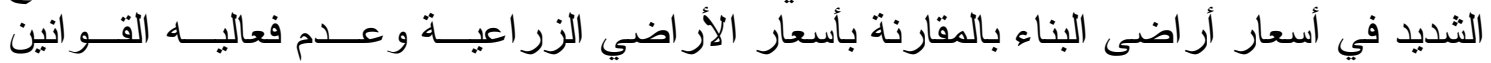

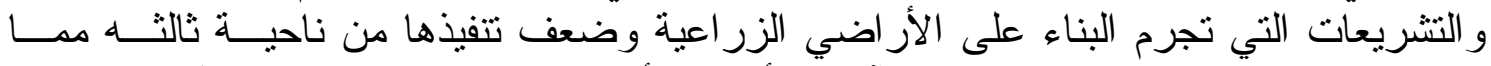

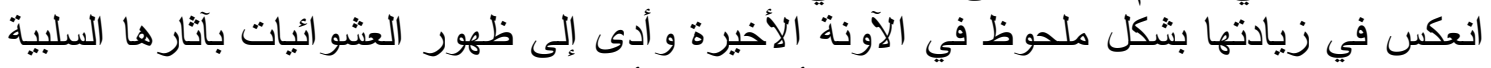

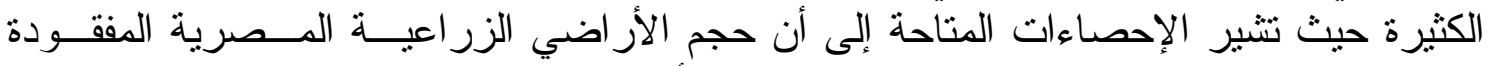

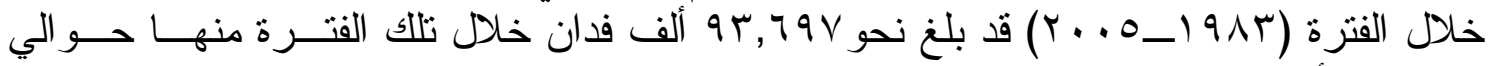

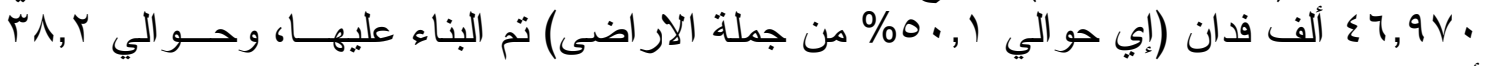

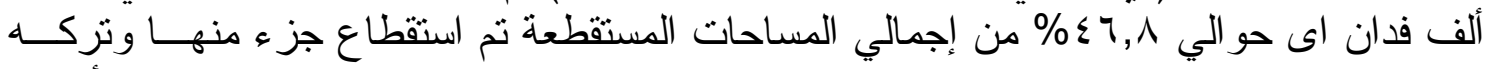

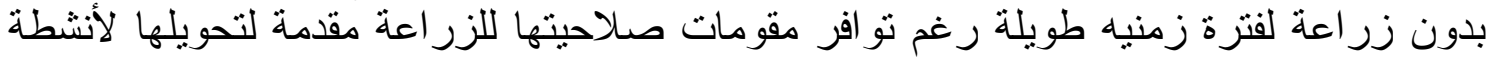

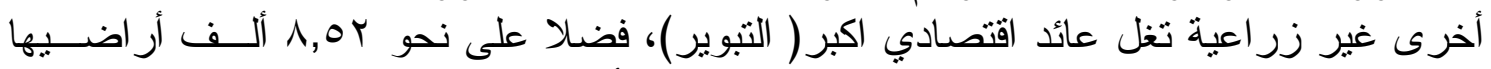

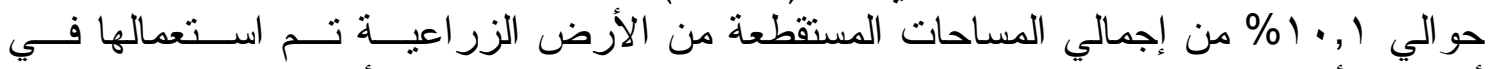

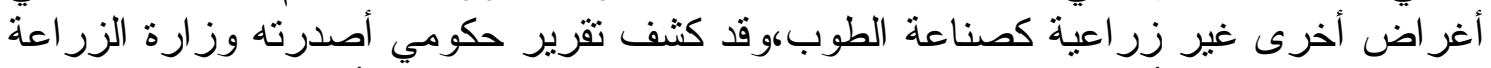

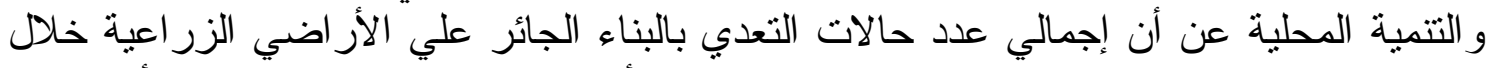

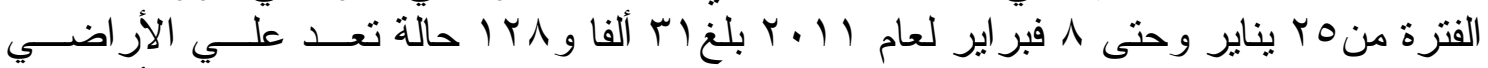

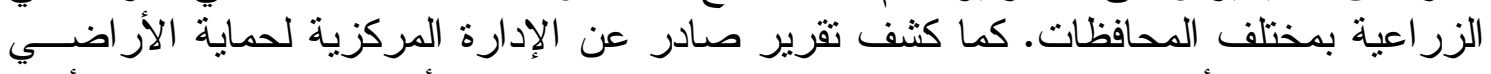

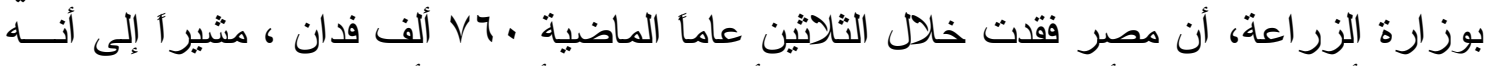

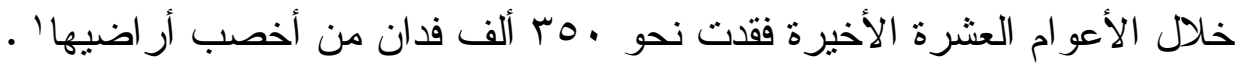

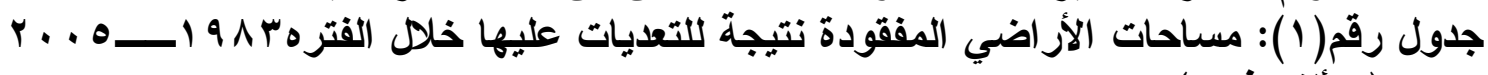

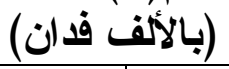

\begin{tabular}{|c|c|c|c|c|c|}
\hline جمله & $Y \ldots 0-97$ & $1990-94$ & $199 r-\wedge 1$ & $19 \wedge V_{-} \wedge r$ & نوع التعدي \\
\hline$r \Lambda, Y, r$ & & $11,1.9$ & 17,TYY & $1 \cdot, \leqslant 7)$ & التبوير \\
\hline$\Lambda, O Y O$ & & $\cdot, 0 \leqslant 7$ & $r, \wedge \circ r$ & $\varepsilon, 1 Y V$ & التجريف \\
\hline$\varepsilon \neg, 9 \vee$. & $11, v \leqslant r$ & $\varepsilon, \cdot \Gamma)$ & $1 T, 97 \varepsilon$ & IV,YMY & البناء \\
\hline $94,79 V$ & $11, v \leqslant r$ & 10,070 & $r \varepsilon, \varepsilon \leqslant \wedge$ & $r 1, \wedge r$. & جمله \\
\hline
\end{tabular}

1ز اره الزر اعة، الإدارة المركزية لحماية الار اضى، بيانات غير منشورة، القاهرة؛ ا.ب 
المصدر:- وز اره الزر اعة واستصلاح الأر اضي، الإدارة المركزية لشئون حماية الأر اضــي، إدارة الإحـــاء،

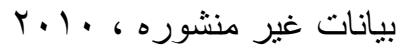

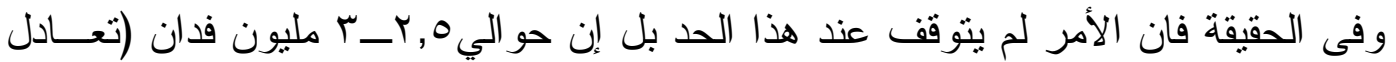

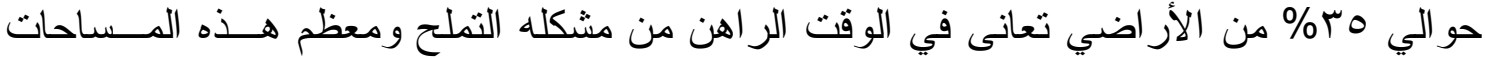

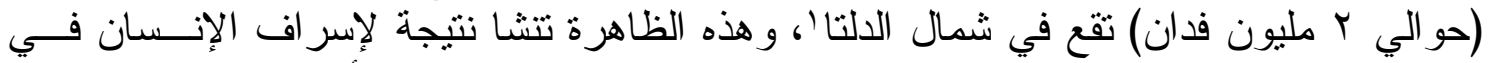
استخدام مياه الري من ناحية و عدم الاهتمام بالصرف الزئ الزي اعي من ناحية أخرى، كما تعد الميــاه

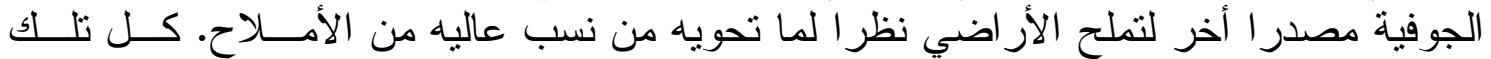

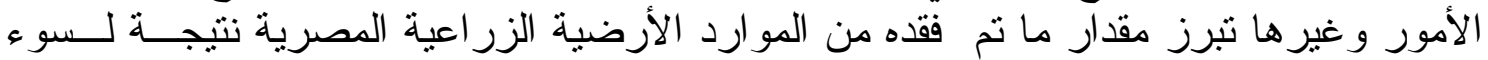

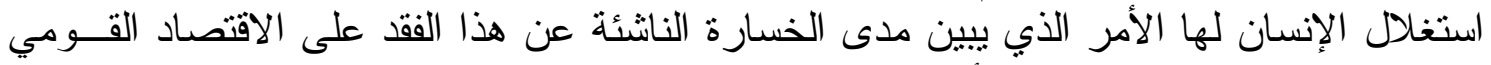

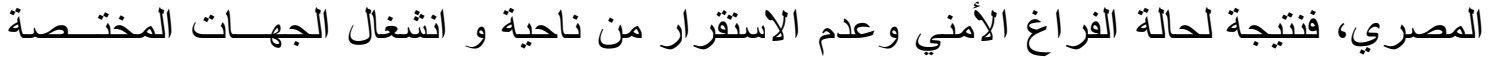

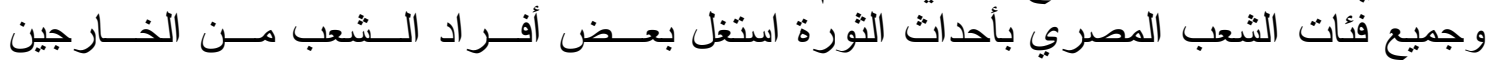

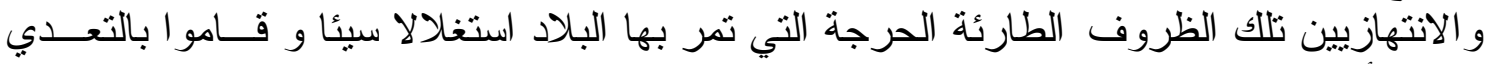

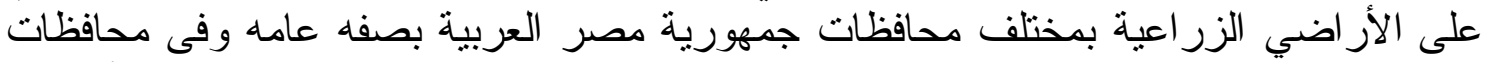

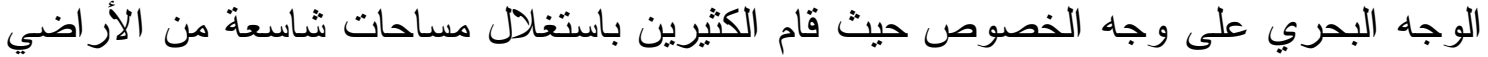

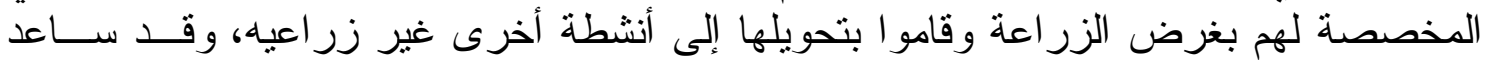

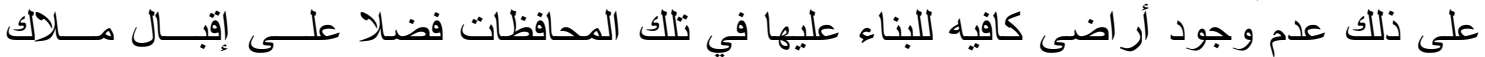

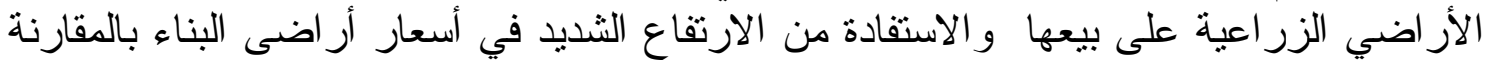

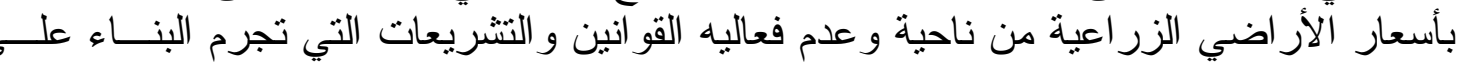

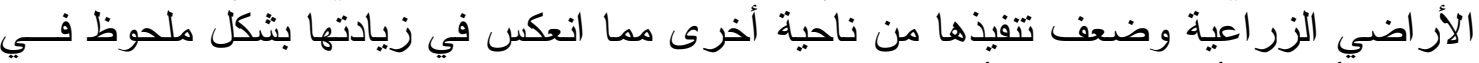

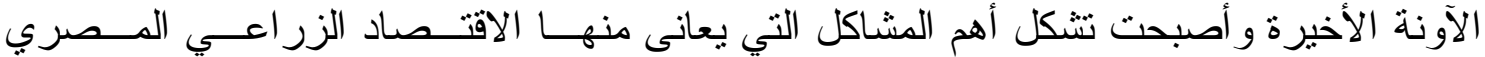

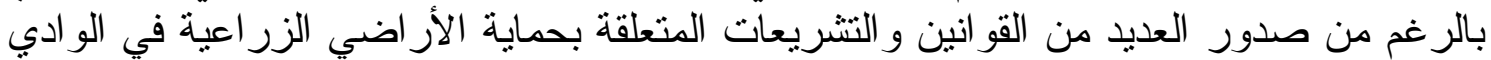

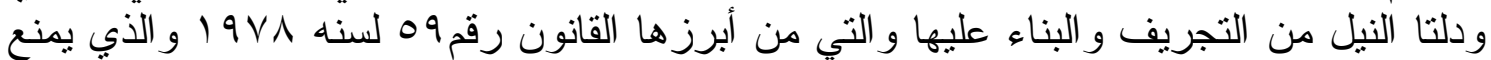

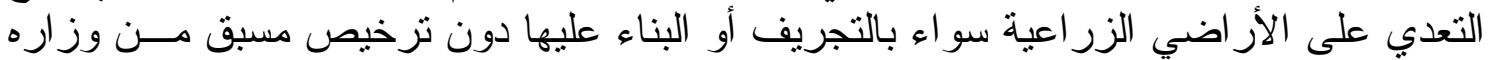

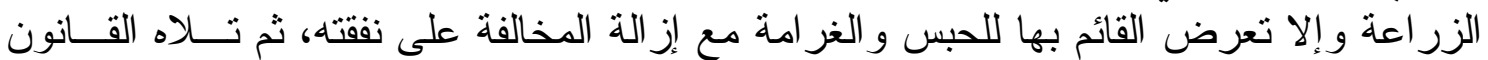

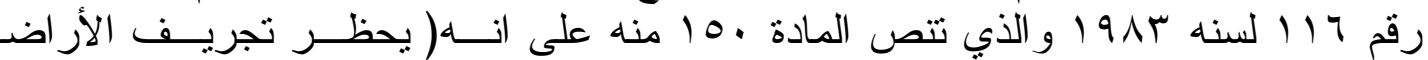

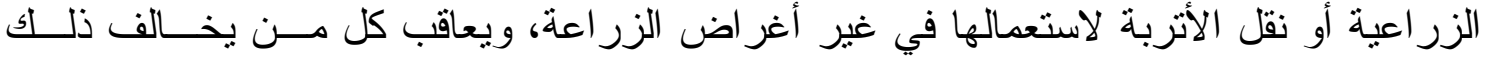

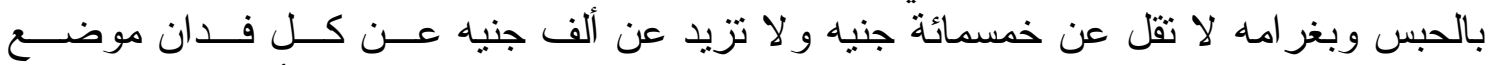

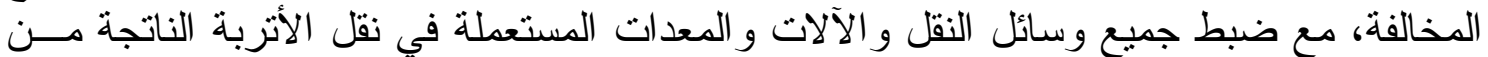

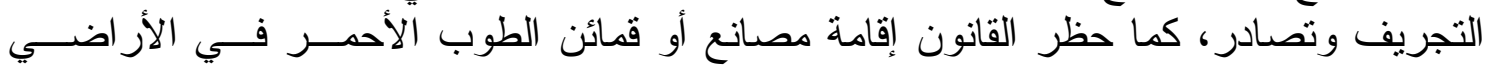

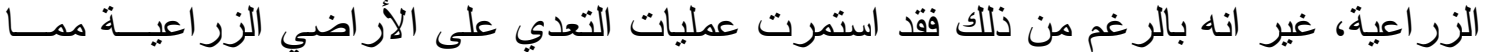

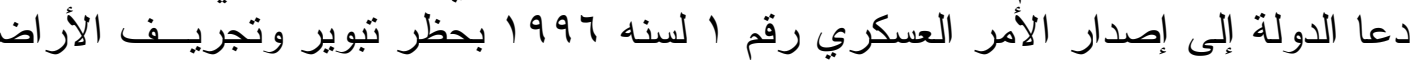

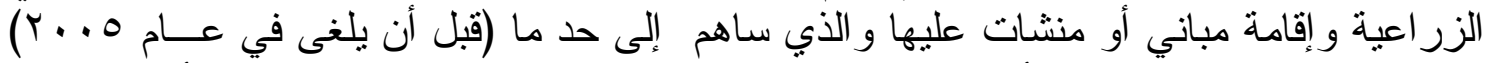

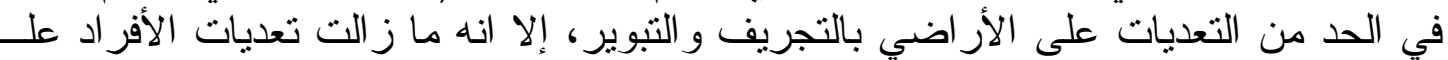

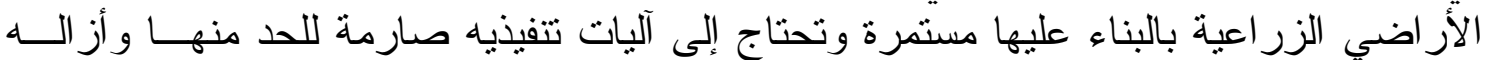

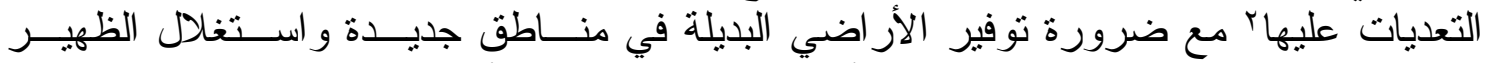

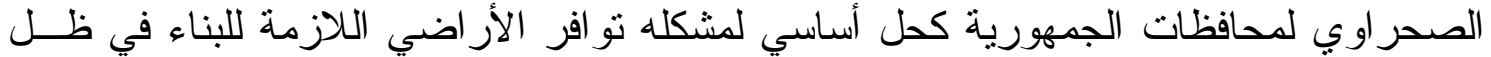

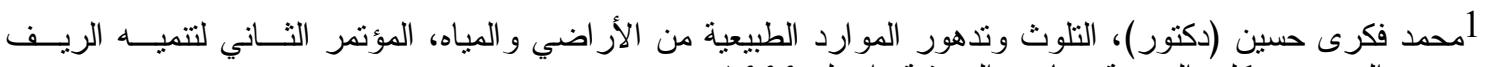

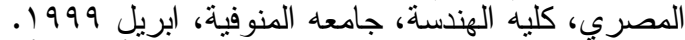

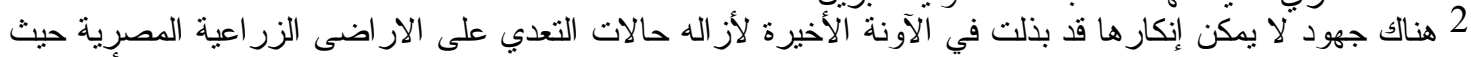

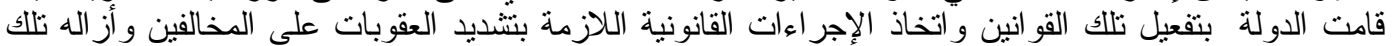
التعديات على حساب المعتدين. 


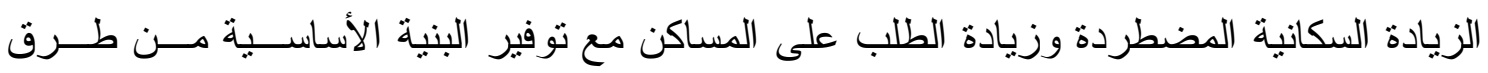
وخطوط مو اصلات و غير هان.

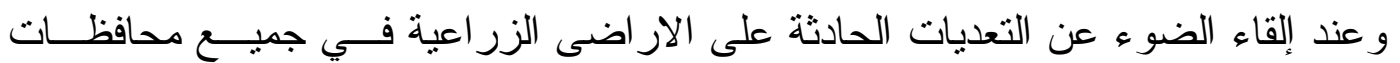

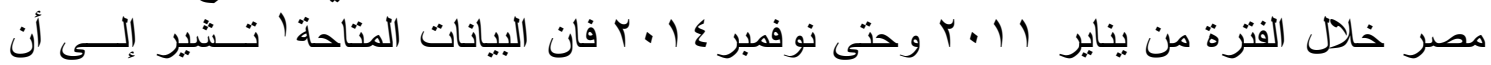

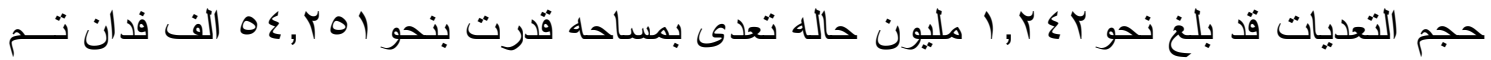

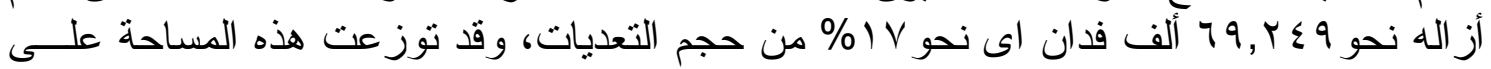

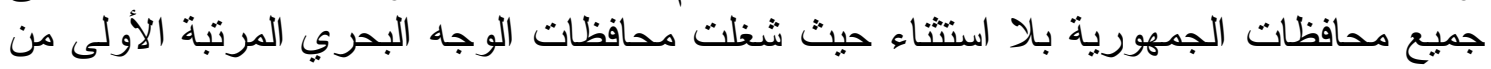

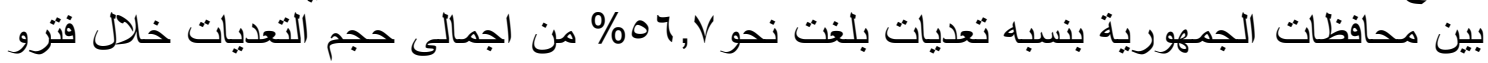

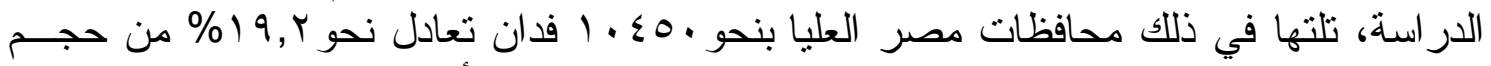

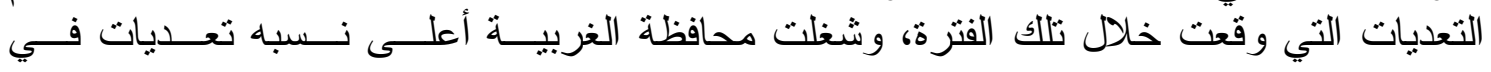

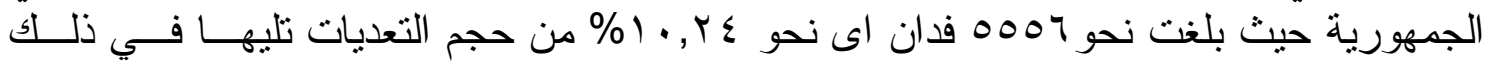

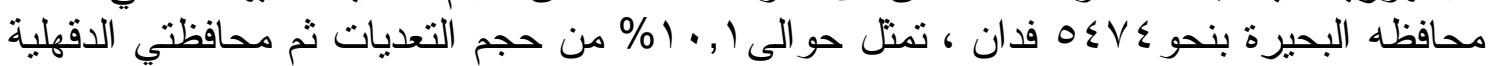

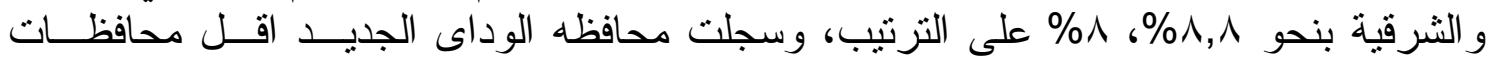

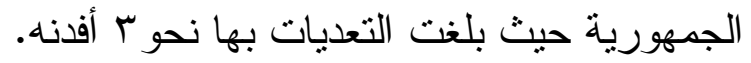

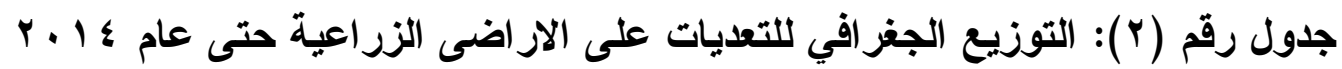

\begin{tabular}{|c|c|c|c|c|c|c|c|}
\hline ترتيب & $\%$ & عدد الحالات & ترتيب & $\%$ & فدان المساحة & جله الزرقعة & المحافظة \\
\hline IV & $\cdot, r \wedge$ & $\varepsilon \wedge \neg$. & r & $\cdot, \varepsilon \varepsilon$ & rr人 & $1 V, 7 V$. & القاهرة \\
\hline $1 \leq$ & $1,0 \mathrm{~V}$ & $190 \%$. & IV & $1, V T$ & $9 \mu \wedge$ & $1 V 0,90 T$ & الإسكندرية \\
\hline 19 & $\cdot, 1 \leq$ & $1 V$. & $r \varepsilon$ & $\cdot, \cdot 7$ & ro & $01, \mu \vee V$ & بورسعيد \\
\hline$r$. & $\cdot, \cdot r$ & rᄉI & $r \cdot$ & $\cdot, 00$ & rqq & $r V, \cdot Y I$ & السويس \\
\hline- & 1,99 & $r \leqslant V V I$ & & $r, V \wedge$ & 101. & YVY,,$Y I$ & جمله \\
\hline 11 & • & r995 & 11 & . & גו" & rT, & إسماعيلية \\
\hline$r$ & $11,0 \mathrm{~V}$ & $1 \leq K V \mid \Lambda$ & $r$ & $1 \cdot, 1$ & $0 \leqslant V \leqslant$ & MT,ITH & البحيزة \\
\hline $1 T$ & $1,9 \leq$ & $r \leq 111$ & 10 & $r, \varepsilon 1$ & $M \cdot V$ & $1.9,898$ & دمباط \\
\hline 19 &., .0 & 70974 & $\mathrm{~V}$ & $7, M$ & $r \leqslant Y \tau$ & $71 Y, 104$ & كفر الشيخ \\
\hline$r$ & $9, \leqslant 7$ & 118017 & 1 & $1 \cdot, r$ & 0007 & 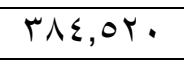 & الغزبية \\
\hline 7 & $V, 7 Y$ & 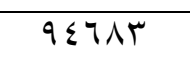 & $r$ & $\wedge, \wedge$ & $\varepsilon \vee \vee q$ & $707, \mathrm{VAV}$ & الدقهلية \\
\hline 0 & $\Lambda, r$ & 1.191. & $\varepsilon$ & $\Lambda, \cdot$ & $\varepsilon r r q$ & $\Lambda \cdot r, V \leq V$ & الشرقية \\
\hline 1 & $I r, \Sigma \Lambda$ & $10 \leqslant 99 V$ & YI & $\cdot, \vee \vee 0$ & $\varepsilon 7 \cdot V$ & $r V \cdot, Y \backslash T$ & المنوفية \\
\hline \multirow[t]{2}{*}{$\varepsilon$} & $\wedge, 71$ & $1 . r q 1 r$ & 0 & $V, \leqslant 1$ & $\varepsilon \cdot Y \mu$ & $1 \wedge \varepsilon, \varepsilon r q$ & القليوبية \\
\hline & $70, r$ & $\Lambda 1 \cdot \lambda 11$ & & $07, V$ & $r \cdot v \leqslant q$ & $\varepsilon q \mid V, r \cdot \varepsilon$ & جمله \\
\hline IT & $\cdot, 1 T$ & rч^9. & 17 & $1, \wedge \mu$ & 991 & YIY,A70 & الجيزة \\
\hline IT & $r, V_{1}$ & rut & $1 T$ & $r, \cdot$ & 1709 & $\varepsilon Y q, \wedge) \wedge$ & الفيوم \\
\hline 1. & $\Gamma, \wedge \mu$ & $\Sigma \vee O \wedge \wedge$ & IT & $r, 0$ & $19 \ldots$ & $r \wedge \wedge, r q 9$ & بنى سويف \\
\hline \multirow[t]{2}{*}{$\Lambda$} & $7, r$ & 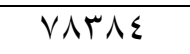 & 7 & $7, \wedge$ & rVII & $\varepsilon \wedge 0, \vee 0 \uparrow$ & المنيا \\
\hline & $\varepsilon \wedge, 19$ & $09171 Y$ & & 10,1 & AYTI & $1 \leq 17, \vee \mu \wedge$ & جمله \\
\hline V & 7,7 & $\wedge) \wedge \leq \Lambda$ & $\Lambda$ & 0,7 & $r \cdot r \varepsilon$ & $r \leq r \cdot V \cdot I$ & أسيوط \\
\hline 9 & $0, \pi \leqslant$ & フาะก & 9 & $0, \varepsilon$ & YqYO & MIV,70V & سوهاج \\
\hline 11 & $r, r$ & $\varepsilon \varepsilon V \mid \varepsilon$ & 1. & $\varepsilon, V$ & ros & $r \varepsilon l, r$. & قنا \\
\hline 10 & $1, \varepsilon$ & $1 V \leqslant 0 \leqslant$ & $1 T$ & $r, \cdot$ & 1709 & $\varepsilon 0, Y Y \backslash$ & الأقصصر \\
\hline 17 & • & $\Sigma 1 \ldots$ & YY & $\cdot, 00$ & r91 & $1 \wedge 7,9 \ldots$ & أسوان \\
\hline
\end{tabular}

1 وزاره الزر اعة، الإدارة المركزية لحماية الار اضى، بيانات غير منشورة، القاهرة؛ ا. ب 
Assiut J. Agric. Sci., (46) No. (2) 2015 (281-291)

ISSN: 1110-0486

Website: http://www.aun.edu.eg/faculty_agriculture/arabic_E-mail:ajas@aun.edu.eg

\begin{tabular}{|c|c|c|c|c|c|c|c|}
\hline & $I V, Y V$ & $19 V .91$ & & $19, r$ & $1 . \leqslant 0$. & $|r T \varepsilon \cdot 7|$ & جمله \\
\hline YI & $\cdot, \cdots \leq$ & or & rT & $\cdot, \ldots \varepsilon$ & $r$ & $|r V, O H|$ & الو ادي \\
\hline$r$. & $\cdot, \cdot 1$ & 1.1 & ro & $\cdot, \cdots V$ & $\varepsilon$ & $r \cdot T, \leqslant V V$ & مطروح \\
\hline & $\cdot, 19$ & $r \leqslant \leqslant$. & TV & $\cdot, r$ & $10 \mathrm{~V}$ & & النوبارية \\
\hline & $1 \ldots$ & IYEYYOS & & $1 \ldots$ & $0 \leqslant Y 01$ & $\wedge \leqslant 1 \cdot, 9 \wedge 7$ & الإجمالي \\
\hline
\end{tabular}

المصدر :- جمعت وحسبت من بيانات وز اره الزر اعة و استصلاح الأر اضي، الإدارة المركزية لحماية الار اضـسى،

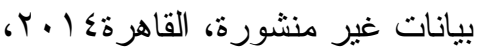

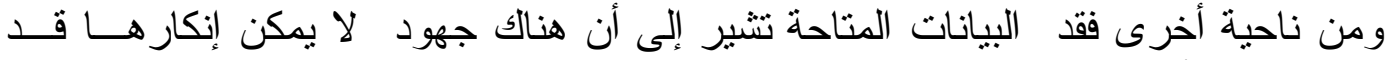

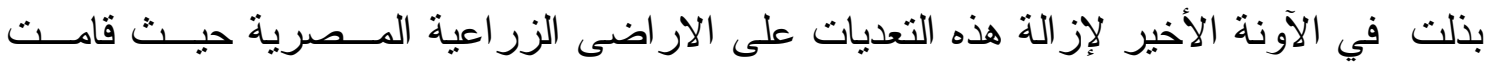

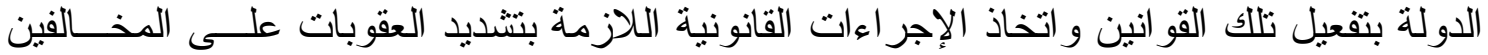

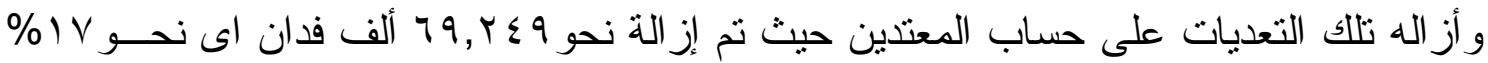

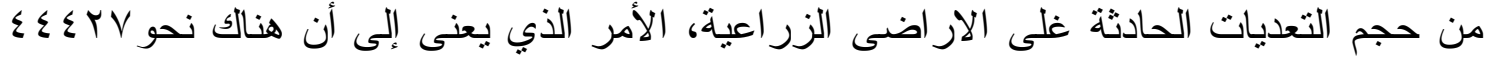

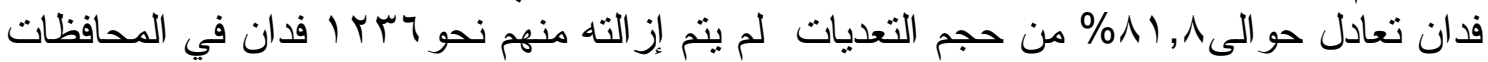

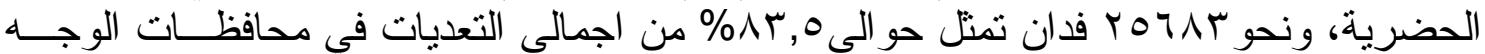

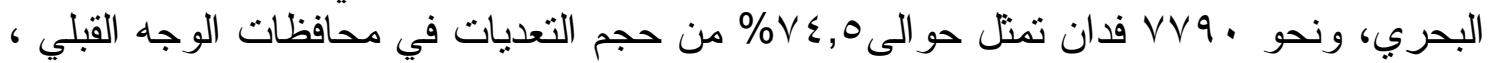

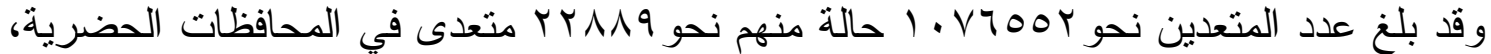

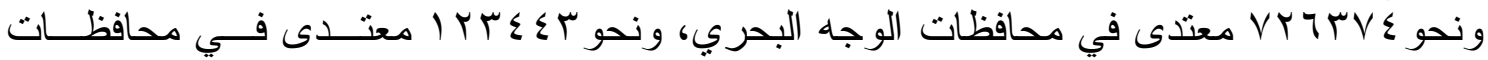

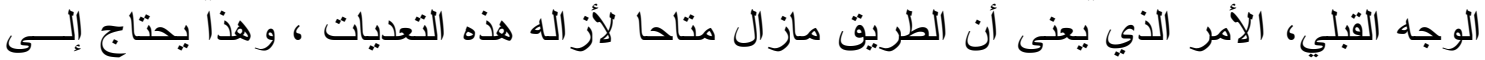

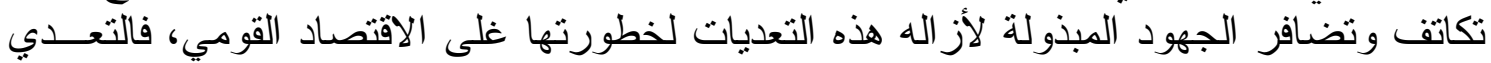

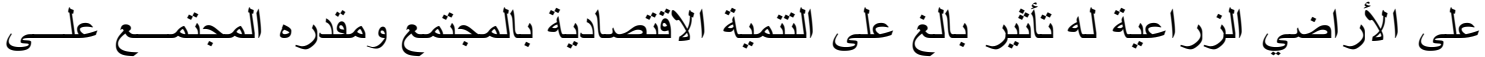

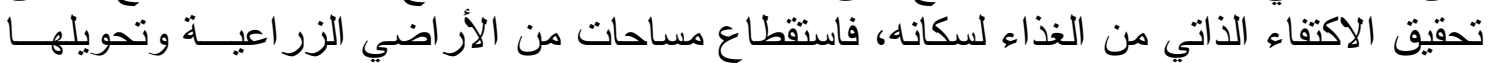

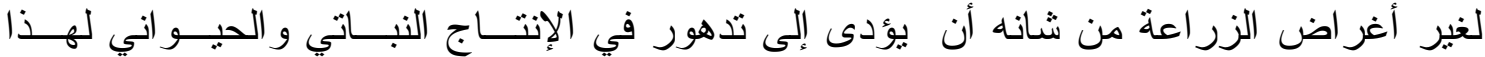

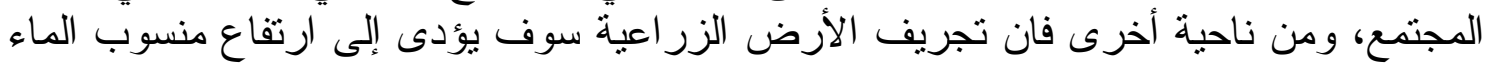

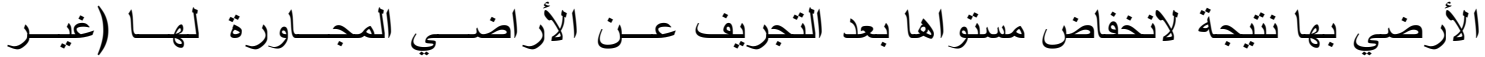

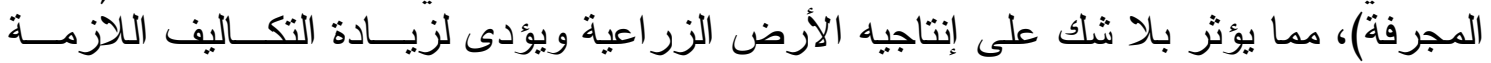

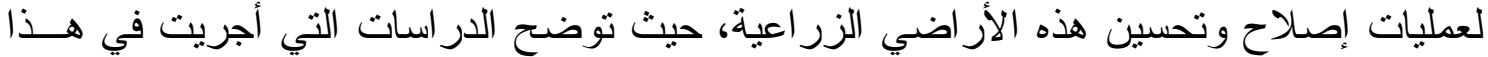

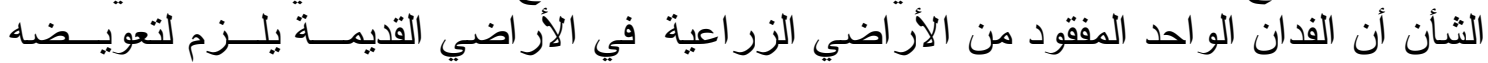

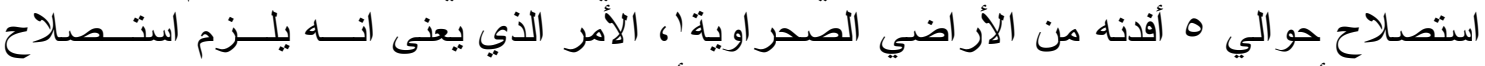

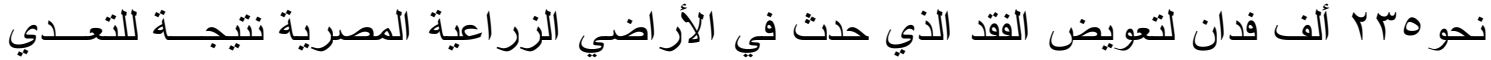

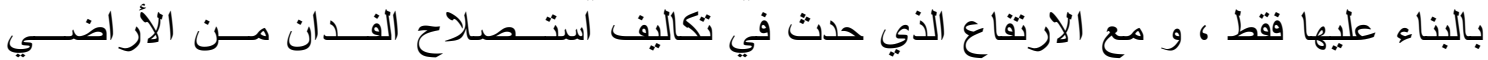

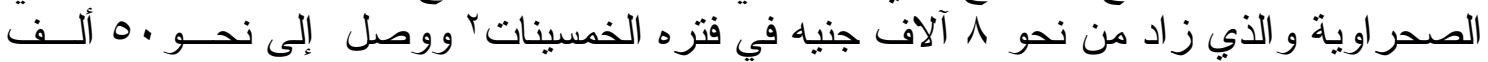

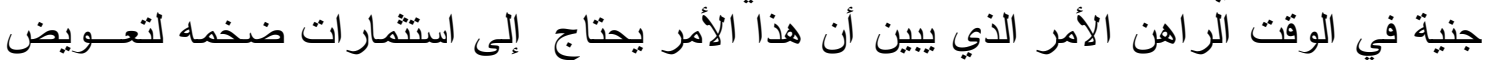

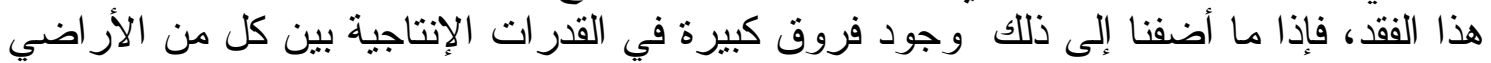

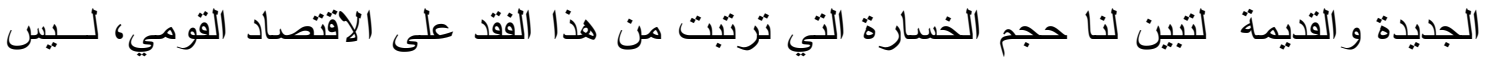

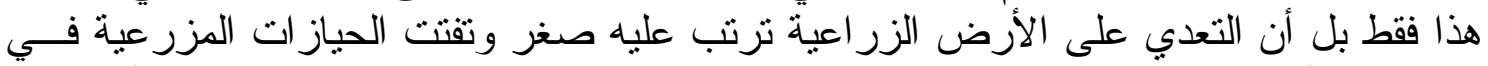

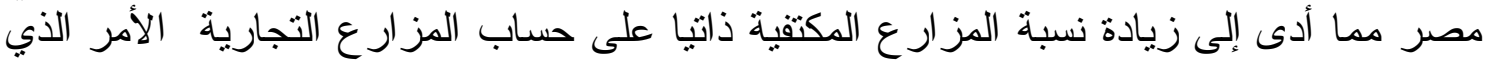

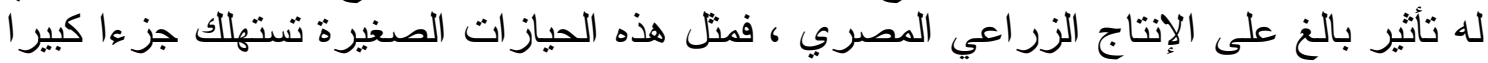

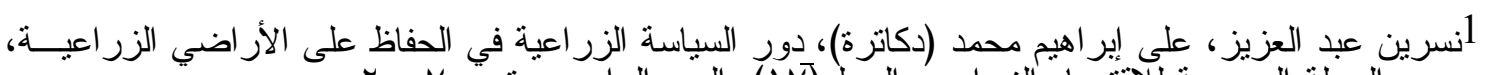

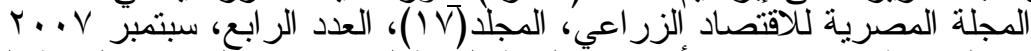

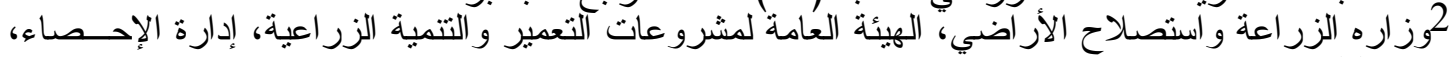
بيانات غير منشورة الزرة النئه 


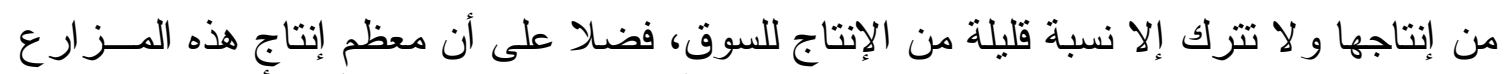

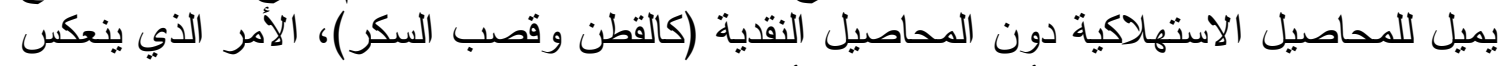

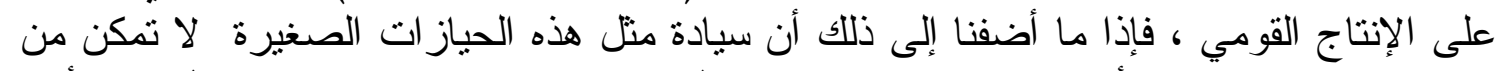

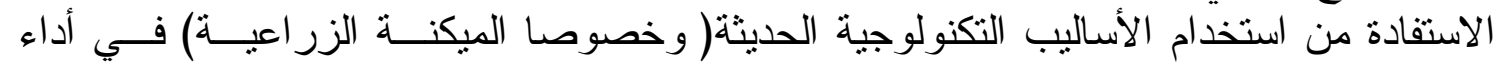

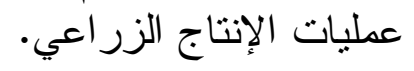


Assiut J. Agric. Sci., (46) No. (2) 2015 (281-291)

Website: http://www.aun.edu.eg/faculty_agriculture/arabic

ISSN: 1110-0486

جدول رقم (ب): التوزيع الجغرافي لما تم ازالتة ونسبتهم من التعديات على الاراضى الزراعية

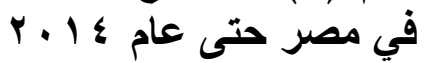

\begin{tabular}{|c|c|c|c|c|}
\hline \% من المتعدين & عدد المعتدين & \% من التعديات & فدانة & المحافظة \\
\hline 9,11 & $\sum \wedge \uparrow$. & $9 \cdot, r$ & TT & القاهرة \\
\hline$V, 9 T$ & $190 \%$. & vi,. & 110 & الإسكندرية \\
\hline$r 1, \Lambda$ & IV. & $\wedge 0, \mathrm{~V}$ & 0 & بورسعيد \\
\hline$T, \cdot Y$ & rᄉI & $V \vee, 1$ & 71 & السويس \\
\hline$\Lambda, r$ & $r \leqslant V V I$ & 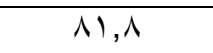 & TV乏 & جمله \\
\hline$\sum \vee, V$ & rq9 & $77, r$ & $11 \varepsilon$ & إسماعيلية \\
\hline 7,99 & $1 \leqslant r V \backslash \Lambda$ & $\Lambda \vee, \cdot$ & VI. & البحيرة \\
\hline $9, \leqslant \varepsilon$ & $T \Sigma \| \wedge$ & $\lambda \vee, r$ & 174 & دمياط \\
\hline$V \varepsilon, Y$ & 70974 & $\wedge \wedge, \Sigma$ & rqv & كفر الشيخ \\
\hline$\Lambda, 19$ & 118017 & $\Lambda V, 0$ & 797 & الغزبية \\
\hline $1 Y, 9$ & qะ7^r & A,, & $9 \cdot r$ & الدقهلية \\
\hline$r \wedge, \varepsilon$ & 1.191. & $V 1, r$ & $I Y \leqslant V$ & الثرقية \\
\hline $9, \wedge$ & $10 \leqslant 99 \mathrm{~V}$ & 94,9 & TVA & المنوفية \\
\hline $1 \cdot, 7$ & $1.491 Y$ & $\Lambda 7, r$ & $00 Y$ & القليوبية \\
\hline $1 \cdot, \varepsilon$ & $11 \cdot \wedge 11$ & $\Lambda r, 0$ & 0.74 & جمله \\
\hline$r_{0, r}$ & rчAq. & $0 \wedge, 0$ & $T V \varepsilon$ & الجيزة \\
\hline $0,1 Y$ & rrTVI & $9 \Gamma, \cdot$ & 110 & الفيوم \\
\hline$r, 01$ & $\sum \vee ० \wedge \wedge$ & $9 \leqslant, 9$ & NI & بنى سويف \\
\hline$r 1,9$ & VAイヘ乏 & 77,7 & ITHA & المنيا \\
\hline 0,9 & $09171 Y$ & $V q, r$ & $1 V \cdot 1$ & جمله \\
\hline 17,0 & $\Lambda \backslash \wedge \leq \Lambda$ & $\Lambda \cdot, \Lambda$ & ov9 & أسيوط \\
\hline $1 r, 9$ & $77 \leqslant r 4$ & $\wedge r, T$ & $\varepsilon r$. & سوهاج \\
\hline$r \wedge, r$ & $\varepsilon \varepsilon V \backslash \leqslant$ & $70, \varepsilon$ & $\Lambda .7$ & قنا \\
\hline$\sum \vee, 1$ & $1 V \leqslant 0 \leqslant$ & $01, Y$ & $\Lambda \cdot \Lambda$ & الأقصر \\
\hline $10, r$ & $\varepsilon 1 \ldots$ & $9 \vee, \varepsilon$ & rv & أسوان \\
\hline$r Y, 1$ & $19 V .91$ & $V \leqslant, 0$ & r74. & جمله \\
\hline $7 V, 9$ & or & $0 \wedge, 0$ & TY & الوادي \\
\hline$r v, T$ & 1.1 & $r v, 0$ & 0 & مطروح \\
\hline$T r, r$ & $T \leq \varepsilon$. & $\sum 7,1$ & 19 & النوبارية \\
\hline $1 \varepsilon, \varepsilon$ & To9 & $\sum \vee, V$ & $\sum 7$ & جمله \\
\hline IV & IY $Y Y Y O E$ & $\wedge 1, \wedge$ & $9 \vee \leqslant 9$ & الإجمالي \\
\hline
\end{tabular}

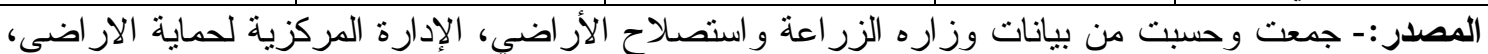

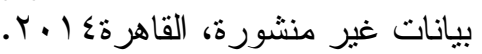


جدول رقم ( ) ): التوزيع الجغرافي للمتبقي من التعديات على الاراضى الزراعية في مصر حتى

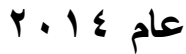

\begin{tabular}{|c|c|c|c|c|}
\hline \% من المتعدين & عدد المتعدين & \% من التعديات & فلمسانة & المحافظة \\
\hline $9 \cdot, 9$ & $\varepsilon \varepsilon 1 V$ & $q \cdot, r$ & r10 & القاهرة \\
\hline$V 7, V$ & $1 \leqslant 9 \lambda 1$ & $V I, \cdot$ & sor & الإسكندرية \\
\hline$V \lambda, Y$ & ITr & $\Lambda 0, \mathrm{~V}$ & $r$. & بورسعيد \\
\hline 94,9 & 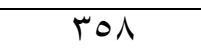 & $V V, 1$ & r.o & اللويس \\
\hline 91,1 & YYAMA & $\wedge 1, \wedge$ & DTY & جمله \\
\hline$\varepsilon \varepsilon, 1$ & IVT. & $77, r$ & TYS & إسماعيلية \\
\hline $9 \pi,$. & דוצדאיואו & $\Lambda \vee, \cdot$ & $\varepsilon V T \varepsilon$ & البحيرة \\
\hline $9 \cdot, 0$ & Y\^乏. & $\Lambda V, r$ & $11 \leqslant 1$ & دمياط \\
\hline$r 0, r$ & ITVYI & $\Lambda \Lambda, \varepsilon$ & $r \cdot r q$ & كفر الثيخ \\
\hline 91,1 & $1 . \vee \wedge 9 \leqslant$ & $\Lambda V, 0$ & \&ลT. & الغربية \\
\hline $00, \varepsilon$ & $O Y \leqslant Q Y$ & ᄉ), & TAVT & الدقهلية \\
\hline$V 1, T$ & VYवYI & $V I, Y$ & $r \cdot 19$ & الشرقية \\
\hline$T r, V$ & QVYYY & $9 r, 9$ & $\varepsilon r r q$ & المنوفية \\
\hline$\wedge 9, \cdot$ & 99011 & $\Lambda \tau, r$ & $r \leqslant v 1$ & القليوبية \\
\hline$\wedge 9,7$ & VYTYVE & Nr,o & roTAr & جمله \\
\hline$V \varepsilon, 0$ & $r \ldots \leqslant\}$ & $0 \wedge, 0$ & TAV & الجيزة \\
\hline $9 \leqslant, 9$ & rI9 & $9 \pi,$. & $10 \leqslant 1$ & الفيوم \\
\hline 97,0 & $\{0917$ & $9 \leqslant, q$ & 1019 & بنى سويف \\
\hline $7 \Lambda, 1$ & orryq & 77,7 & $r \leqslant V \leqslant$ & آلمنيا \\
\hline $9 \leqslant, 1$ & $07 r \pi 91$ & $v q, r$ & 7004 & جمله \\
\hline$\Lambda \uparrow, \xi$ & TAT.O & $\Lambda \cdot, \lambda$ & $r \leqslant \leqslant 0$ & أسيوط \\
\hline$\lambda \vee, \cdot$ & $0 \vee \wedge \leqslant 0$ & $\Lambda \Gamma, T$ & $r 190$ & سوهاج \\
\hline$v 1, v$ & YY.TY & $70, \varepsilon$ & $177 \pi$ & قتا \\
\hline or, o & qrrq & $01, Y$ & $\Lambda \leqslant \wedge$ & الأقصر \\
\hline$\Lambda \varepsilon, \Lambda$ & $r \leqslant V \tau$ & $9 V, \varepsilon$ & YTI & أسوان \\
\hline$T Y, T$ & $T r K \leqslant \leqslant r$ & $V \leqslant, 0$ & VVq. & جمله \\
\hline$r r, 1$ & IV & 01,0 & $T$ & الوادي \\
\hline$T Y, \varepsilon$ & $\pi$ & $r v, 0$ & $r$ & مطروح \\
\hline $9 \lambda, \Lambda$ & $r \leqslant 11$ & $\leqslant 7,1$ & $1{ }^{1} \mathrm{~A}$ & النوبارية \\
\hline$T \leqslant, 0$ & ro 00 & $\varepsilon V, V$ & IVY & جملة \\
\hline$\lambda \Gamma$ & $1.8700 \mathrm{Y}$ & $\Lambda 1, \Lambda$ & $\varepsilon \sum \varepsilon Y V$ & الاجمالى \\
\hline
\end{tabular}

المصدر :- جمعت وحسبت من نفس المصدر السابق

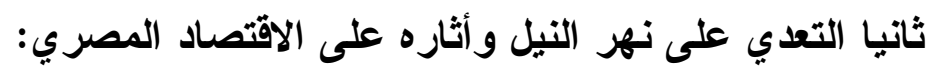

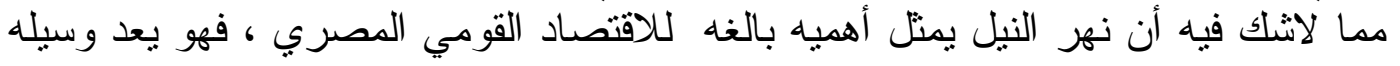

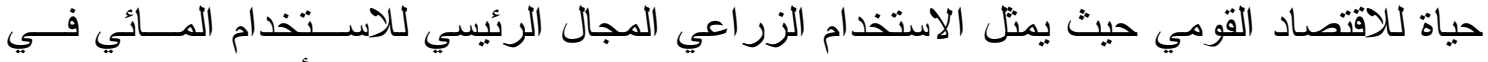

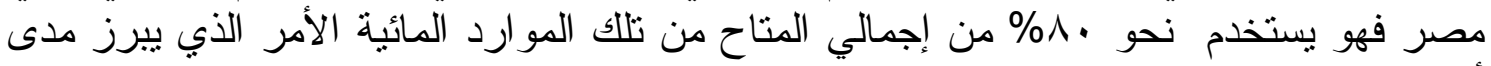

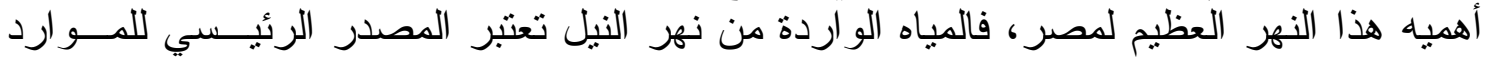

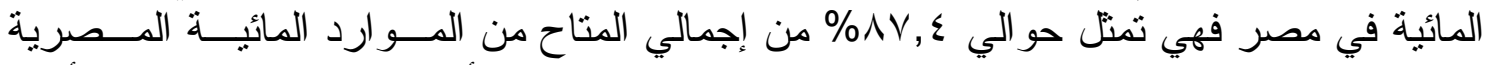

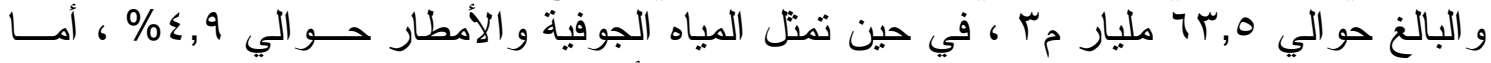

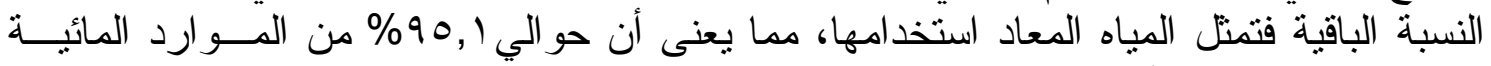

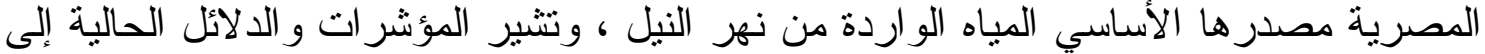

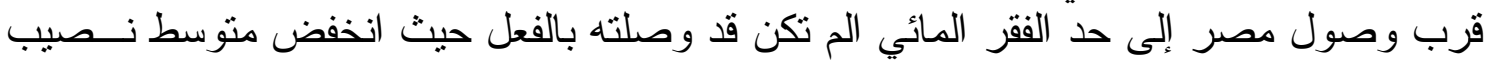




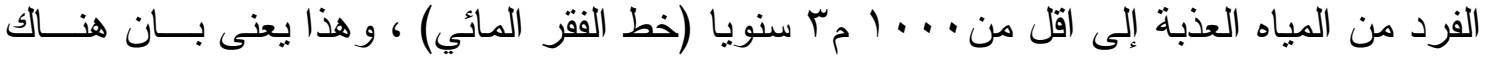

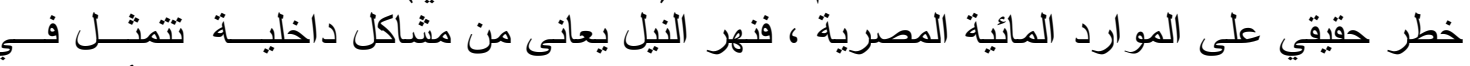

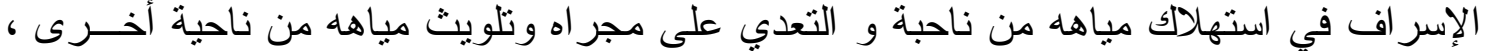

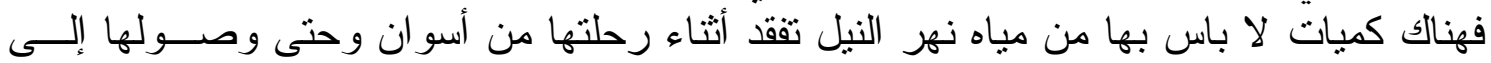

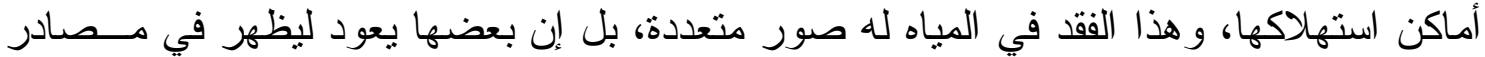

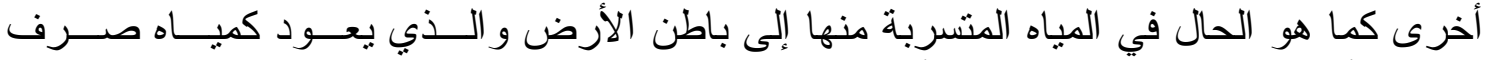

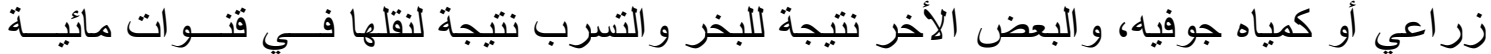

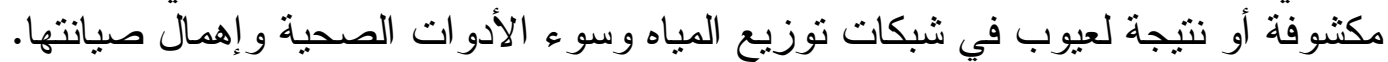

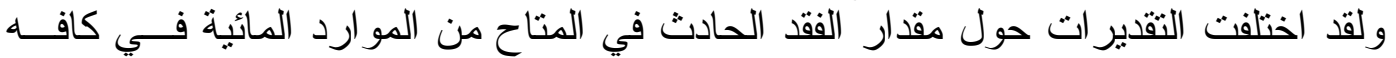

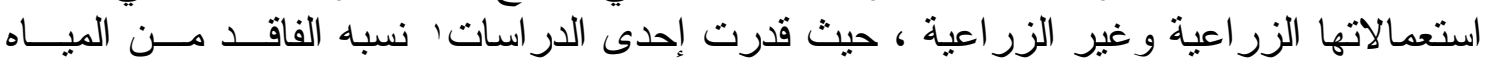

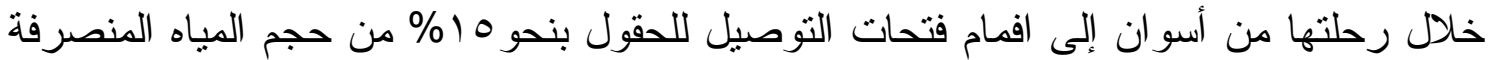

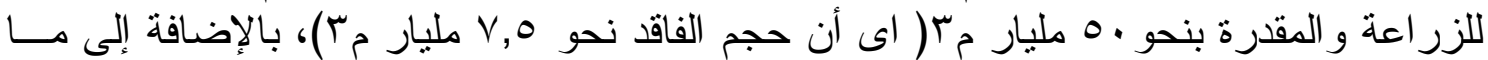

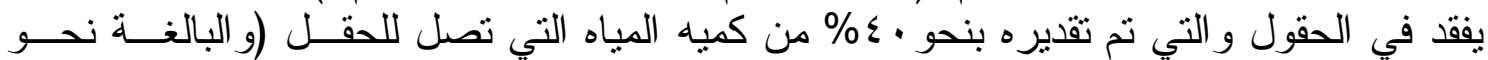

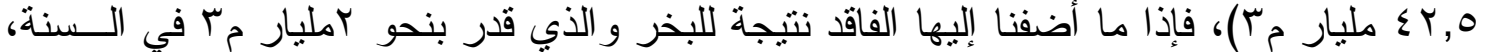

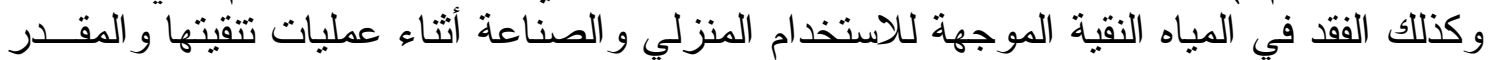

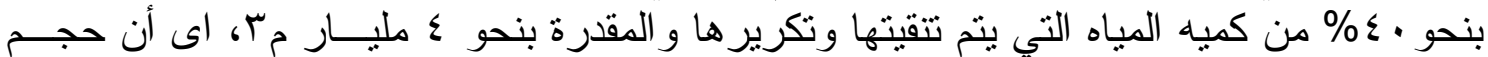

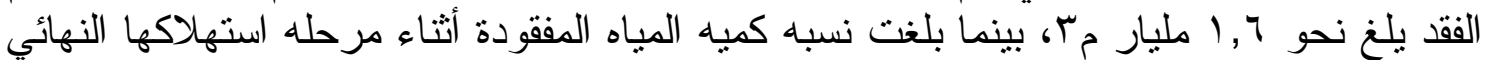

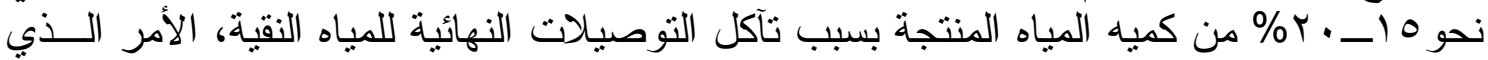

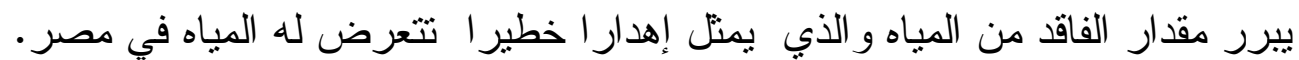

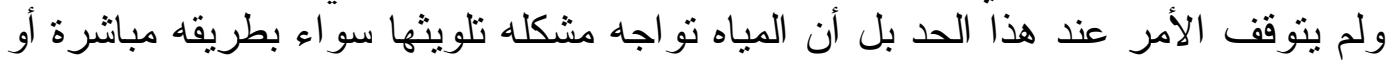

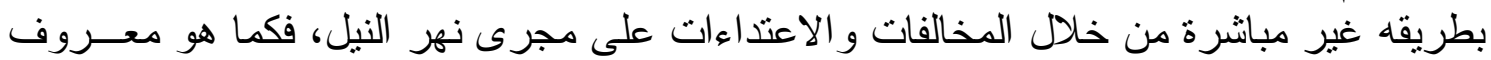

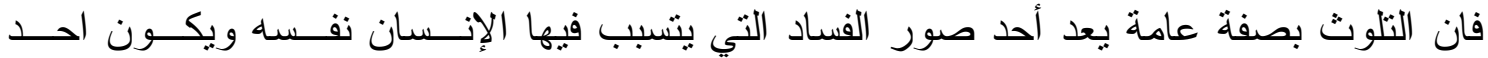

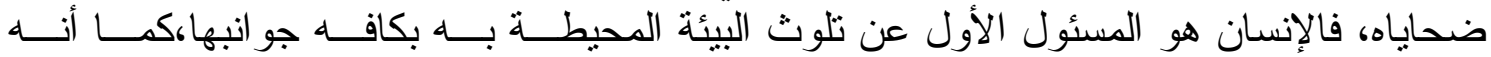

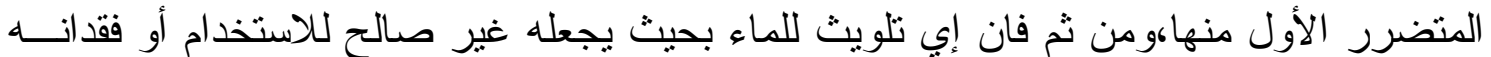

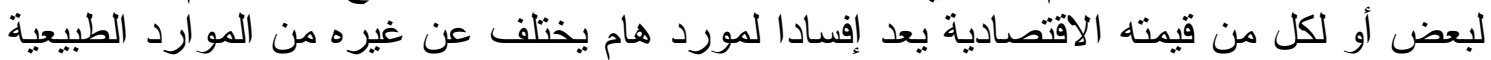

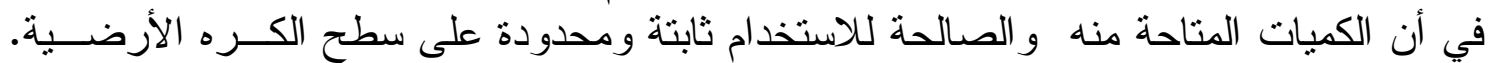

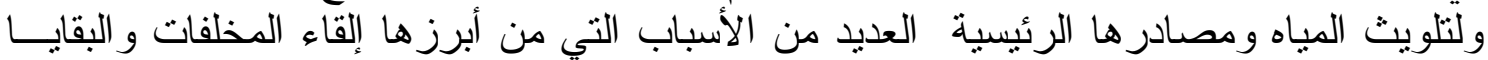

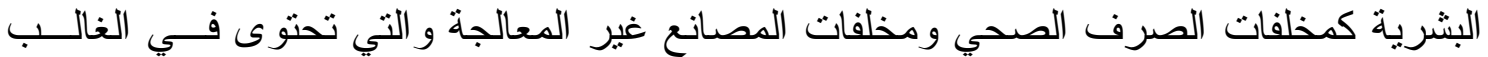

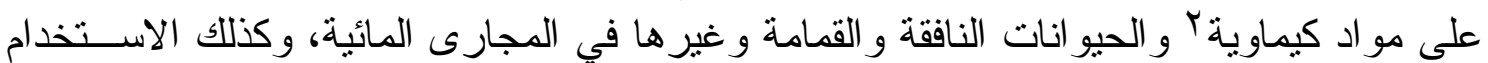

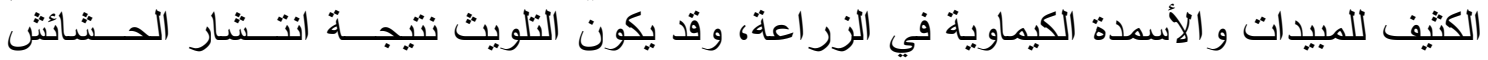

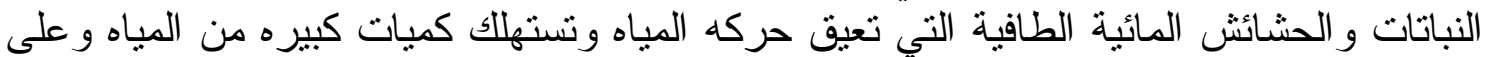

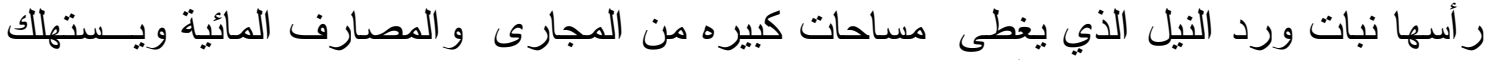

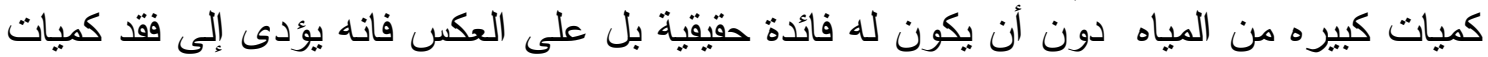

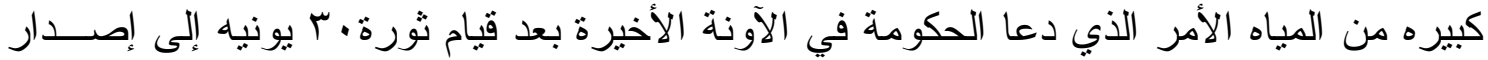

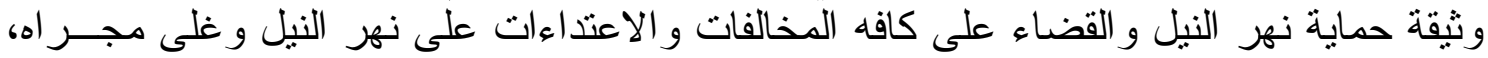

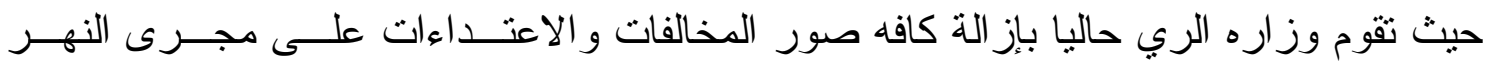

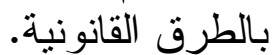

ا محمد مدحت مصطفى (دكتور )، اقتصاديات الموارد المائية، رؤية شــامله لإدارة الميــاه، مكتبـهـه ومطبعـهـ

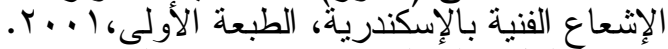

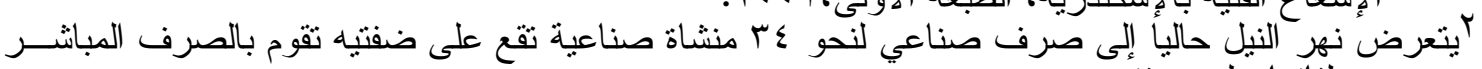
بمخلفاتها على ضفنتيه. 
وفى الو اقع فان التحديات التي تواجه الموارد المائية المصرية لن تتوقف عند هذا الحد بل

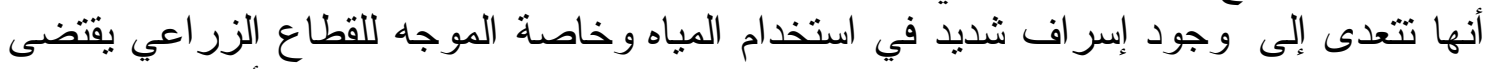

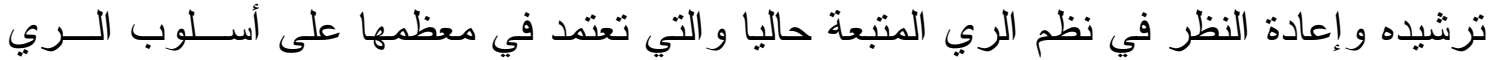

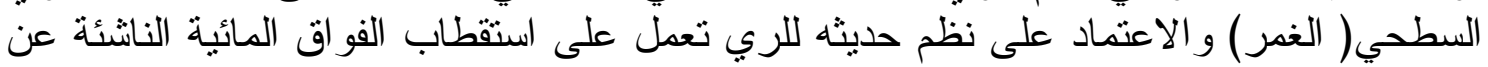

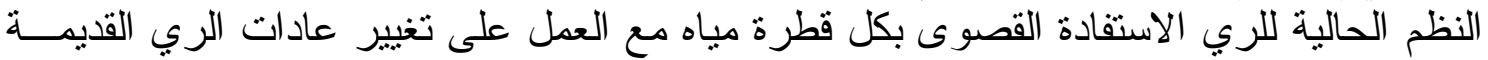

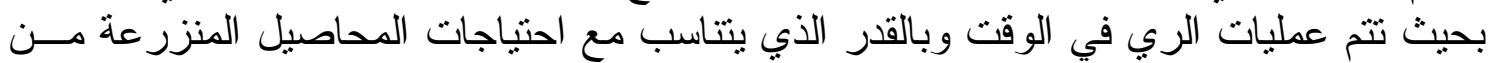

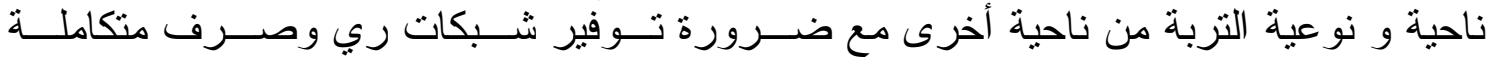

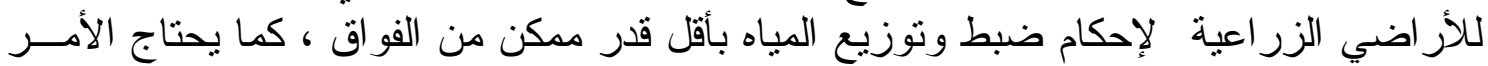

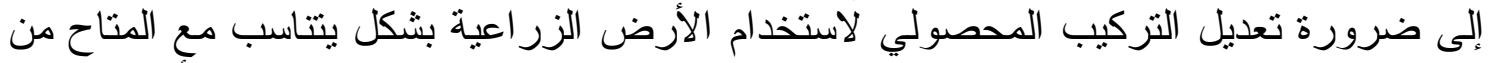

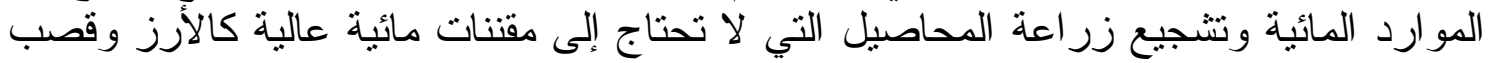

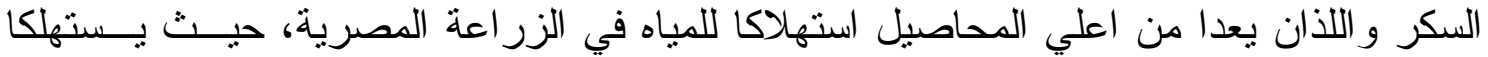

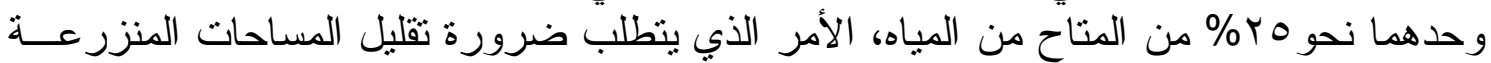

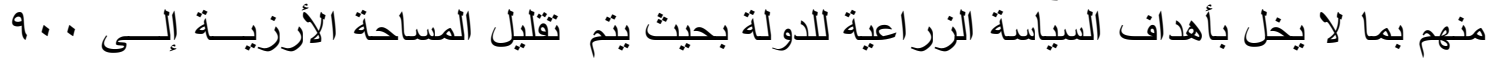

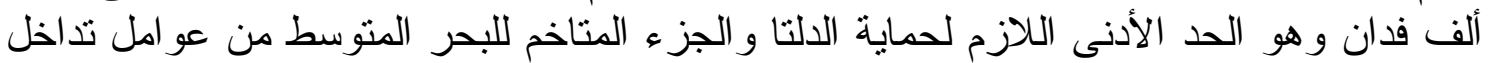

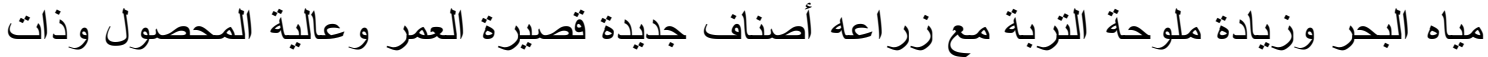

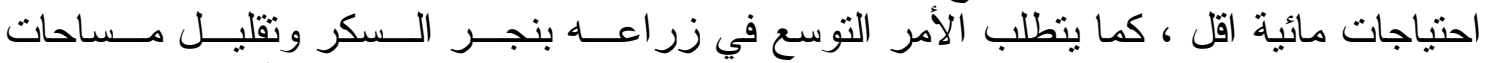

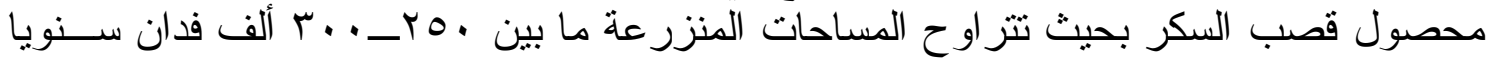

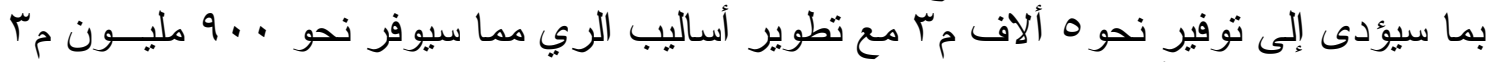

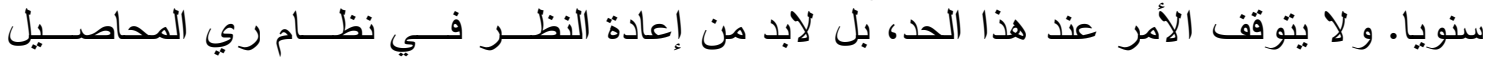

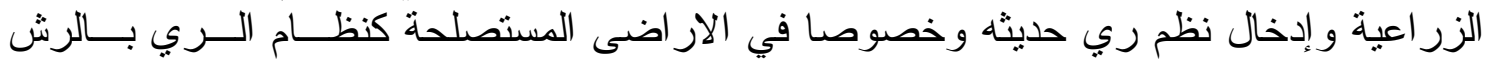

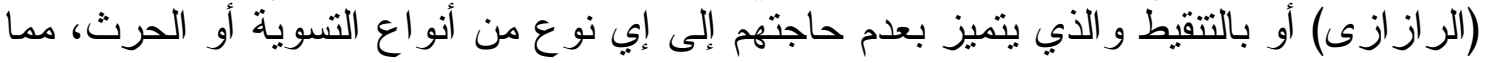

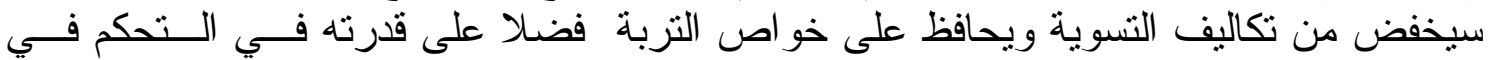
كميات المياه المستخدمة بحيث تتناسب مع قدره التزبة وكذللك قدرته على التحكم فـي كميــات

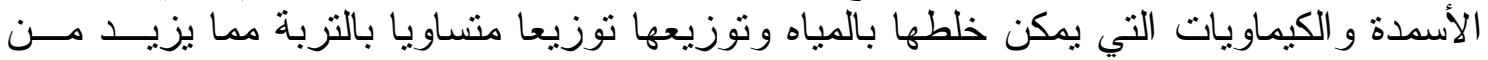

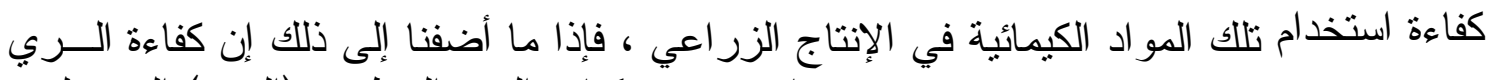

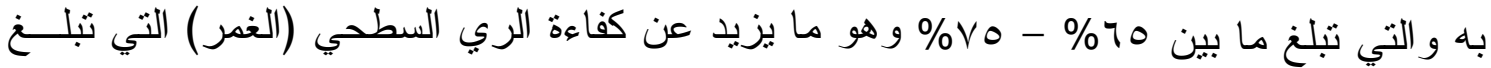

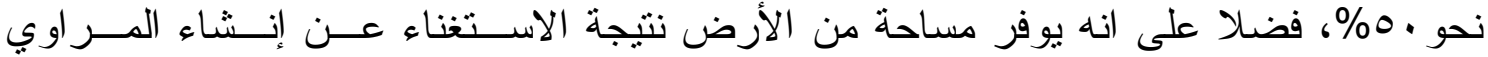

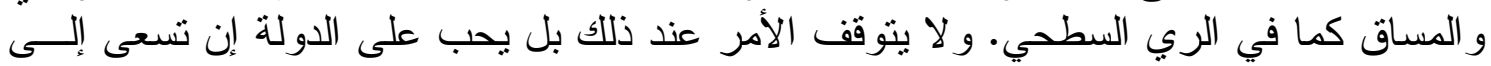

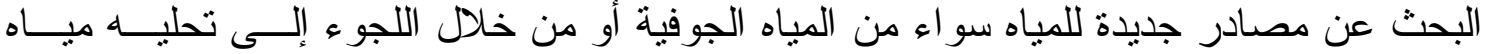

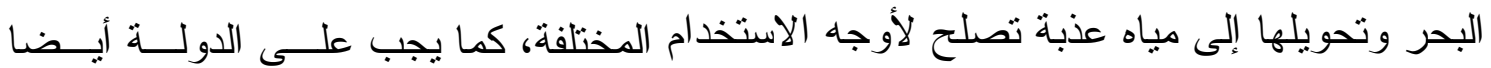

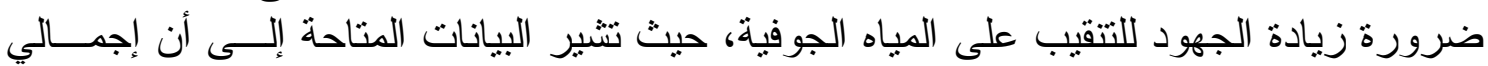

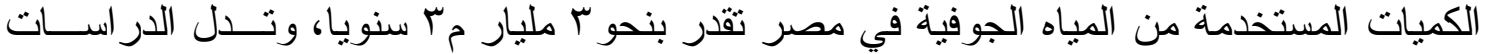

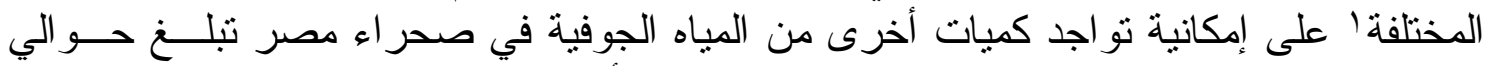

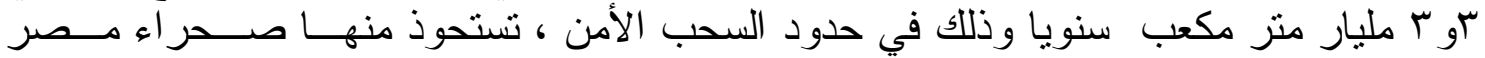

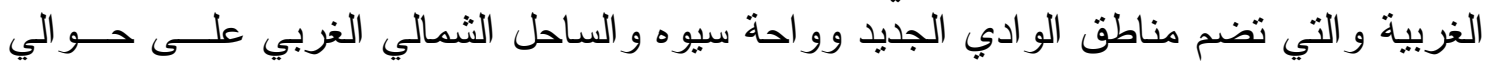

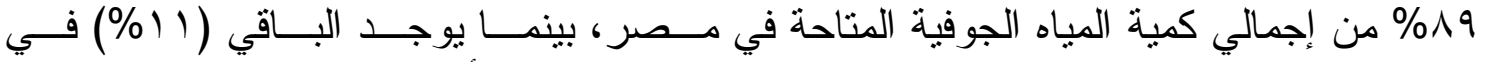

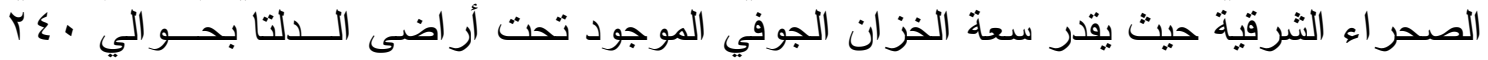

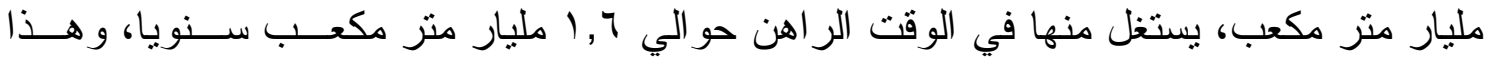

اصلاح على صـالح ( دكتور )، اقتصاديات الار اضى و المياه، قسم الاقتصاد الزر اعي، كليــهـ الزر اعــة، جامعــة 


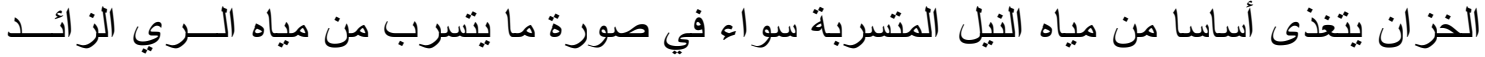

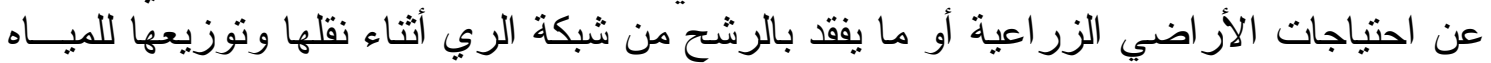

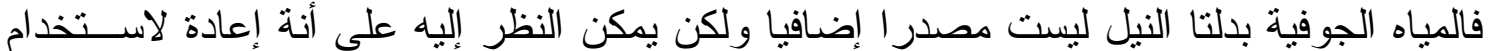

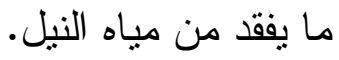

( ) السيد محمد السيد عطا الله، الآثار البيئية للتنمية الاقتصادية الزر اعية، رسالة ماجستير، كليه

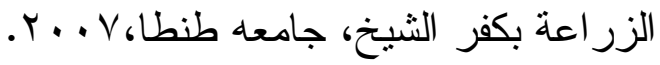

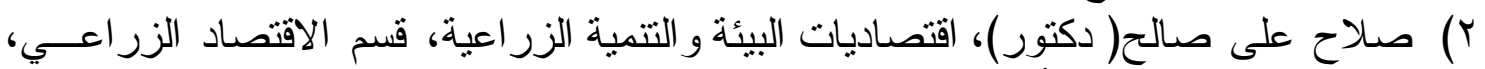

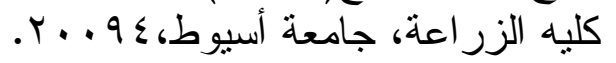

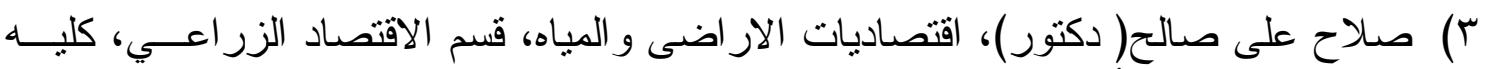

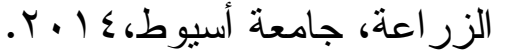

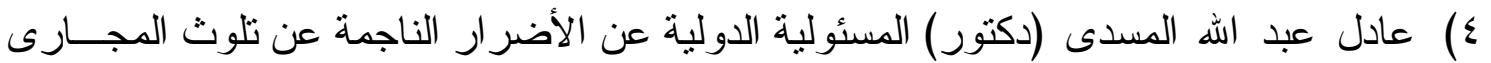

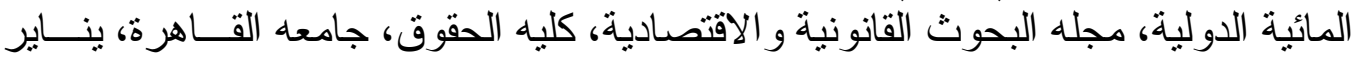
.1999

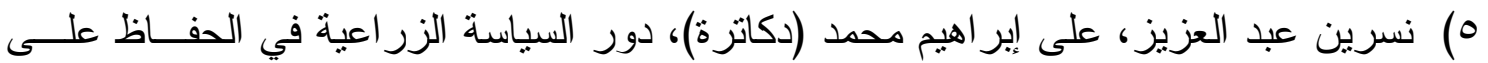

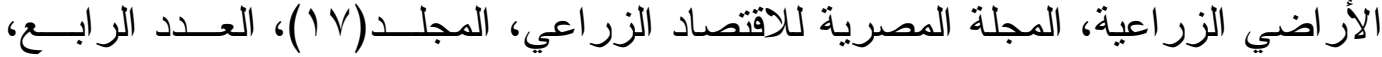

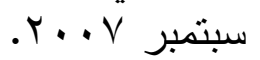

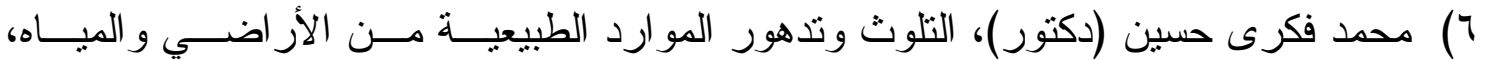

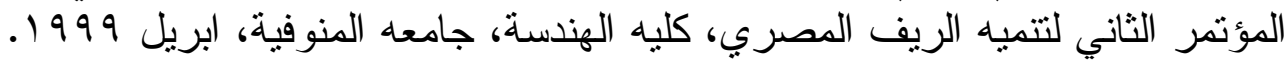

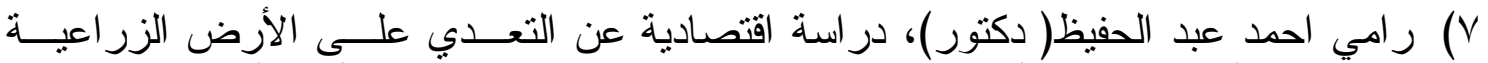

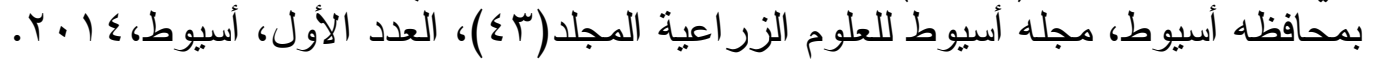

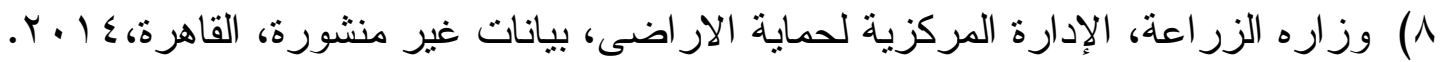

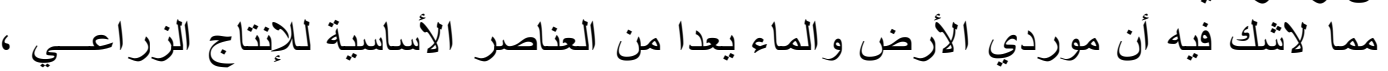

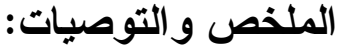

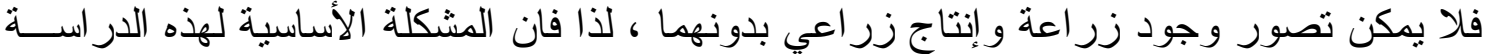

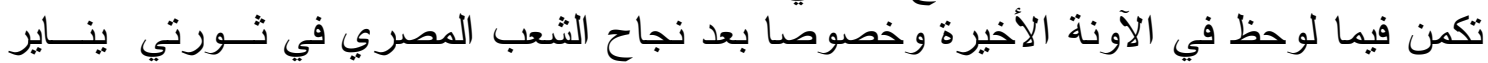

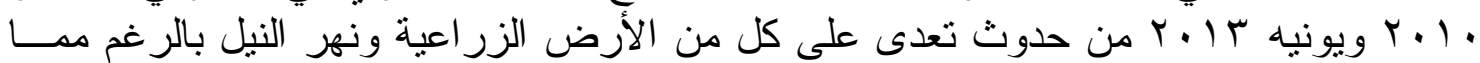

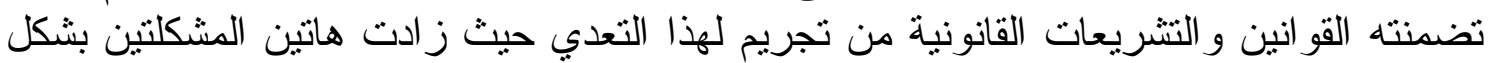

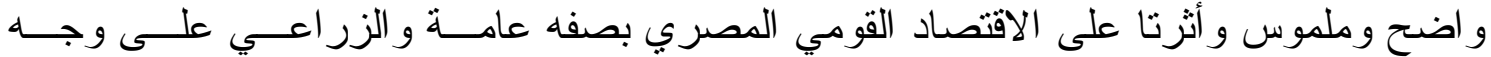

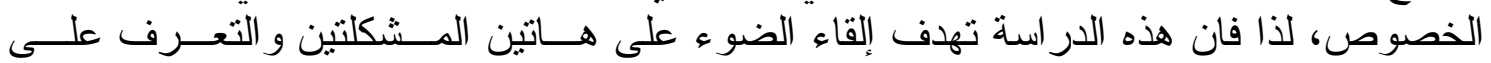

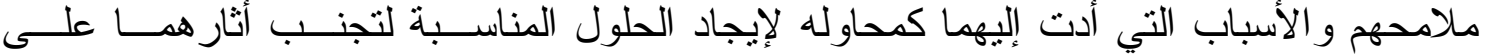

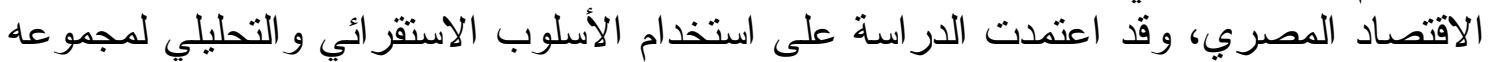

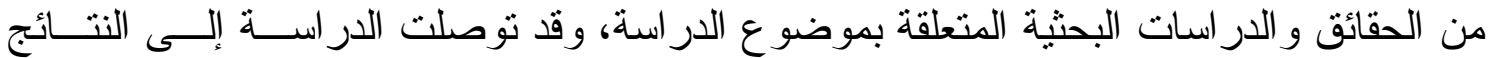




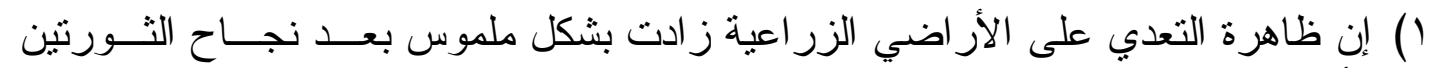

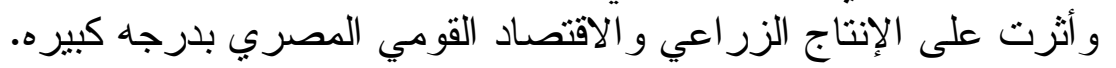

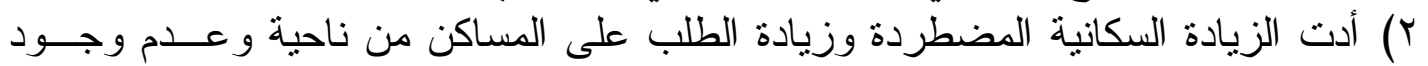

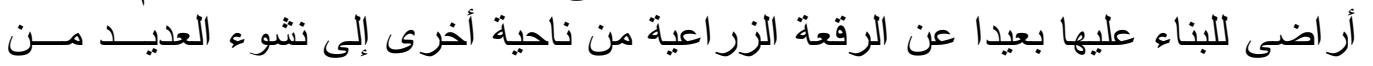
البؤر و المناطق الاستيطانية في العديد من محافظات الجمهورية.

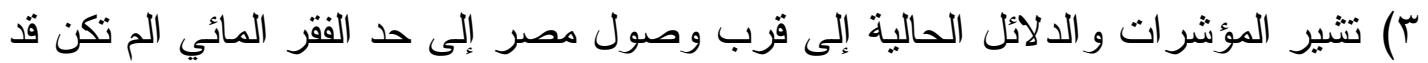

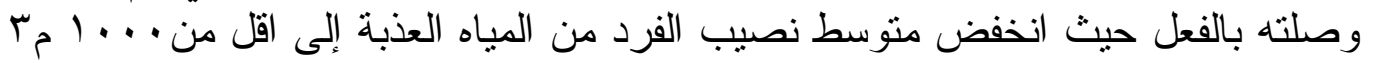

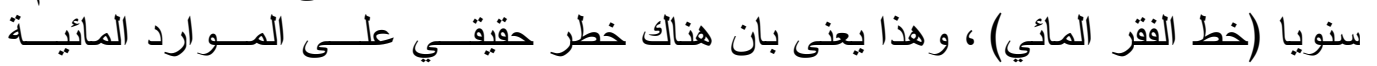
المصرية. ع) تو اجه المياه في مصر نوعين من المشاكل تتمنل في الإسر اف في استهلاكك مياهـــهـ مــن

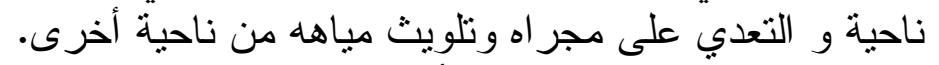

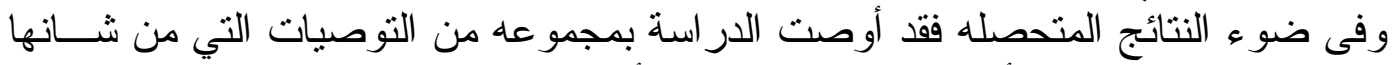
الحد من ظاهرة التعدي على الأرض و على نهر النيل لأثنارهما السيئة على الاقتصاد المصري.

\section{AN Economic Study about Encroachments on Agricultural Land and the RIVER Nile in the Egyptian Economy}

\section{Salah Fadlalla}

Dept. Agricultural Economics, Faculty of Agric., Assiut University

\section{Summary and Conclusion:}

The main objective of the study is to shed light on the encroachment in the area of agricultural and the RIVER Nile in the Egyptian Economy after the refutation of 25 January 2011 and 30 June 2013.

The study indicated that the phenomena of Encroachments on Agricultural Land and the consumption of the Nile water used in agriculture were increased, Also, the study indicated that there a real dangerous in the situation of water.

The study recommended some recommendation to face these problems and its negative effects on the Egyptian economy. 